\title{
Flume Tank Evaluation on the Effect of Liners on the Physical Performance of the Antarctic Krill Trawl
}

\author{
Hao Tang ${ }^{1,2,3,4}$, Bruno Thierry Nyatchouba Nsangue ${ }^{1 *}$, Achille Njomoue Pandong ${ }^{5}$, \\ Pingguo $\mathrm{He}^{6}$, $\mathrm{Xu}$ Liuxiong ${ }^{1,2,3,4}$ and Fuxiang $\mathrm{Hu}^{7}$
}

${ }^{1}$ College of Marine Sciences, Shanghai Ocean University, Shanghai, China, ${ }^{2}$ National Engineering Research Center for Oceanic Fisheries, Shanghai, China, ${ }^{3}$ Key Laboratory of Oceanic Fisheries Exploration, Ministry of Agriculture and Rural Affairs, Shanghai, China, ${ }^{4}$ The Key Laboratory of Sustainable Exploitation of Oceanic Fisheries Resources, Shanghai Ocean University, Ministry of Education, Shanghai, China, ${ }^{5}$ Laboratory E3M, National High Polytechnic School of Douala, University of Douala, Douala, Cameroon, ${ }^{6}$ School for Marine Science and Technology, University of Massachusetts Dartmouth, New Bedford, MA, United States, ${ }^{7}$ Faculty of Marine Science, Tokyo University of Marine Science and Technology, Tokyo, Japan

OPEN ACCESS

Edited by:

Morten Omholt Alver, Norwegian University of Science and Technology, Norway

Reviewed by:

Eduardo Grimaldo,

SINTEF Ocean, Norway

*Correspondence: Bruno Thierry Nyatchouba Nsangue

nsanguet@163.com; nsanguet@yahoo.fr

Specialty section: This article was submitted to Marine Fisheries, Aquaculture and Living Resources, a section of the journa Frontiers in Marine Science

Received: 06 December 2021 Accepted: 31 December 2021

Published: 31 January 2022

Citation:

Tang $H$, Nsangue BTN, Pandong AN, He P, Liuxiong $X$ and Hu F (2022) Flume Tank Evaluation on the Effect of Liners on the Physical Performance of the Antarctic Krill Trawl. Front. Mar. Sci. 8:829615. doi: 10.3389/fmars.2021.829615
The Antarctic krill (Euphausia superba) is one of the most abundant resources in the ocean, which provides food for several important species in the Antarctic Ocean, and is targeted commercially by humans for many decades. To sustainably manage and harvest the species, energy-efficient, catch-efficient, and selective fishing gears should be developed for the Antarctic krill trawl fishery. This study investigates the effect of twine area and the liner length on the engineering performance of trawl through flume tank testing of trawl model to predict the performance of the full-scale midwater trawl used in the Antarctic krill fishery. Four 1/35th scale trawl model nets with varying lengths of the liner, based on the traditional trawl used in the Antarctic krill fishery, were designed using modified Tauti's law and were tested in a flume tank at different towing speed, door spread, heavy bob weight, and the ratio of buoyancy to the fishing line $(F / G)$. The results showed that the reduction in liner length by 25 and 50\% from the traditional trawl net led to the decrease in twine area by 11.01 and $19.31 \%$ and, consequently, resulted in reductions in the lower bridle tension by 12.44 and $19.78 \%$, and increases in energy efficiency by 17.98 and $25.73 \%$, respectively. In addition, the reduction in liner length by 25 and $50 \%$ were found to increase the net mouth opening by 2.63 and $5.38 \%$ and the swept area by 6.52 and $8.38 \%$, respectively, both of which are proportional to catch rates. Although the trawl net with $50 \%$ liner length is more energy-efficient and large mouth opening than those of the trawl net with the liner length over $75 \%$ of the trawl body, the large mesh section without a liner can result in the escape of the krill from the trawl, reducing overall catch efficiency. We, therefore, recommend the trawl with $75 \%$ of liner length as a suitable design for Antarctic krill considering energy efficiency and catch efficiency.

Keywords: Antarctic krill, midwater trawl, liner, flume tank, engineering performance 


\section{INTRODUCTION}

The Antarctic krill (Euphausia superba) is a fundamental component of the complex ecosystem of the Antarctic Ocean (Punchihewa and Krishnarajah, 2013; Bairstow et al., 2021). In fact, it is a mesopelagic species and is a primary prey for several natural predator groups such as bony fishes, penguins, cephalopods, seals, and whales in the Antarctic marine food web (Krafft and Krag, 2015). Additionally, krill is a target species in commercial fisheries for aquaculture feeds and for a growing demand for nutraceuticals, which is believed to prevent certain diseases and strengthen the immune system (Juáres et al., 2018, 2021; Kawaguchi and Nicol, 2020). The Commission for the Conservation of Antarctic Marine Living Resources (CCAMLR) has set precautionary catch limits and catch quotas for the sustainable exploitation of Antarctic krill in order to ensure ecosystem equilibrium, the sustainability of krill fisheries, and to balance the competing interests of Antarctic krill (Wan et al., 2019; Bairstow et al., 2021). Furthermore, the Antarctic krill fisheries also face too many issues such as gear selectivity, energy efficiency, catchability, and ecological sustainability (Wan et al., 2019; Thierry et al., 2022).

The Antarctic krill fisheries have been traditionally conducted using large pelagic trawls, which are towed behind a boat about ten times a day with a catch rate of about 10 tons per tow (Zhou and Feng, 2011; Nicol and Foster, 2016; Feng et al., 2017). The large pelagic trawls used in the Antarctic krill fisheries differ in design and mesh configuration. Some trawls have small meshes throughout the trawl, while others have large meshes in the mouth area with a successive reduction in mesh size toward a small mesh codend (Krafft and Krag, 2015; Herrmann et al., 2018). Pshenikov reported that during the 1970s when the Soviets trawled for krill, only $10-20 \%$ of the krill that entered the trawl opening were retained in the codend (Pshenichnov, 2009). Consequently, the small mesh liners were introduced in both the main body and the codend of large pelagic trawls to reduce the probability of krill escaping through the meshes and increase the retention rate. In fact, the small mesh liners are now widely used in krill trawls and cover various proportions of the trawl body length from $0 \%$ (without liner) to $100 \%$ (covering the entire trawl body) (Xu et al., 2015; Li et al., 2017). These liners are designed as a series of overlapping cones, resulting in a wave motion that gently ripples with the water flow and prevents small organisms from meshing (Engås et al., 2013; Underwood et al., 2016; Zhou et al., 2016). Although the introduction of the small mesh size liner trawl resulted in great increases in the catch, it was observed to move in a wave motion toward the codend, resulting in higher hydrodynamic drag of the trawl system, reduced spread and mouth opening, and lower size selectivity (Engås et al., 2013, 2014; Xu et al., 2015).

The dynamic behavior of trawl nets has been studied for decades using theoretical, experimental, and numerical simulation methods to reduce fuel consumption through the reduction in the net drag ( $\mathrm{Hu}$ et al., 1995; Feng et al., 2017; Lee et al., 2018; Wan et al., 2019; Thierry et al., 2020a). Testing physical models in a flume tank is now considered the de facto standard for evaluating new trawl designs and plays an important role in the modern gear development process
(Winger et al., 2006). Broadhurst et al. (2015, 2017), through model experiments in the flume tank, found that mesh and knot orientations on the trawl body have a significant influence on the prawn trawl resistance and the net mouth opening. Balash et al. (2015) demonstrated from flume tank experiments that mesh orientation ("diamond" vs. "square") did not have much implications on the drag for a prawn trawl. Xu et al. (2015) analyzed and compared the hydrodynamic performance of two small-mesh Antarctic krill trawls of Japanese and Korean designs using flume tank model testing. Underwood et al. (2016) investigated the performance of the small mesh liners as well as options to improve the taper of the trawl and found that the tapering and circumference of the forward part of the liners affected the amount of movement of the liners. Feng et al. (2017) analyzed the hydrodynamic performance of six designs of existing Antarctic krill trawls from Norway, Japan, and Korea and developed a new four-panel Antarctic krill trawl. Wan et al. (2019) designed and analyzed the hydrodynamic performances of a large Antarctic krill trawl (midwater trawl) by numerical simulation and physical model tests and found that the trawl with a large mouth circumference had better hydrodynamic performance and would match with fishing vessels of the class for the efficient production of Antarctic krill. Recently, Thierry et al. (2021a) investigated the hydrodynamic performance of a scaled trawl model using numerical simulations based on the fluid-structure interaction (FSI) method in two-way coupling and the flume tank test based on modified Tauti's law. They found that the numerical results were in good agreement with the flume tank experimental data, and both numerical and experimental results indicated decreases in the drag force with increases in mesh size using Dyneema multifilament twine and decreases in twine diameter using nylon monofilament.

Although the effect of different parameters on the performance of the trawl has been widely studied, the question remains on the effect of liner length on trawl geometry and hydrodynamic forces of an Antarctic trawl krill and optimization of design parameters of the liner to improve engineering and catch the performance of an Antarctic krill trawl. We, therefore, designed four 1/35th scale trawl models with different liner lengths from the traditional trawl commonly used in the Antarctic krill trawl fisheries and tested them in a flume tank under different towing speed, door spread, heavy bob weight, and the ratio of buoyancy to the fishing line $(F / G)$. The aim of this study is to examine the effect of the liner length and twine area on the hydrodynamic forces and geometrical shapes of the Antarctic krill trawl and to optimize the design of the midwater trawl. The findings are expected to contribute to the improvement in the energy efficiency, the spread performance (catch efficiency), and the size selectivity of the krill trawl.

\section{MATERIALS AND METHODS}

\section{Trawl Design and Engineering Model Specifications}

A four-panel midwater trawl that is commonly used in the Antarctic fisheries by Chinese fishing vessels was selected as the trawl design for this study (Figure 1). The circumference of the 


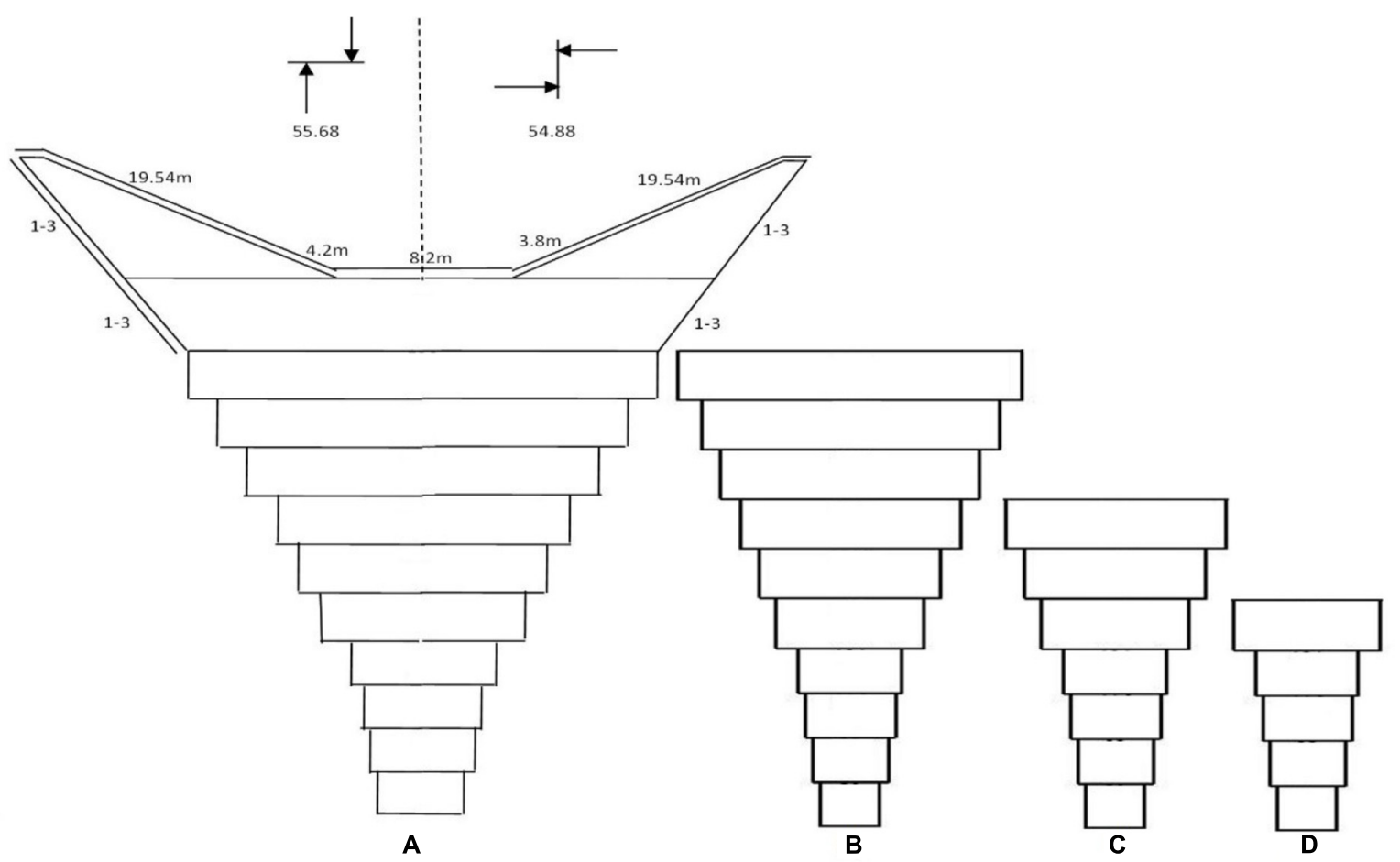

FIGURE 1 | Schematic net plan of $300 \mathrm{~m} \times 132.8 \mathrm{~m}$ (headline: $55.68 \mathrm{~m}$ ) of Antarctic krill trawl (A) including 100\% (B), 75\% (C), and $50 \%$ (D) liners.

TABLE 1 | Characteristics of the full-scale Antarctic krill trawl net.

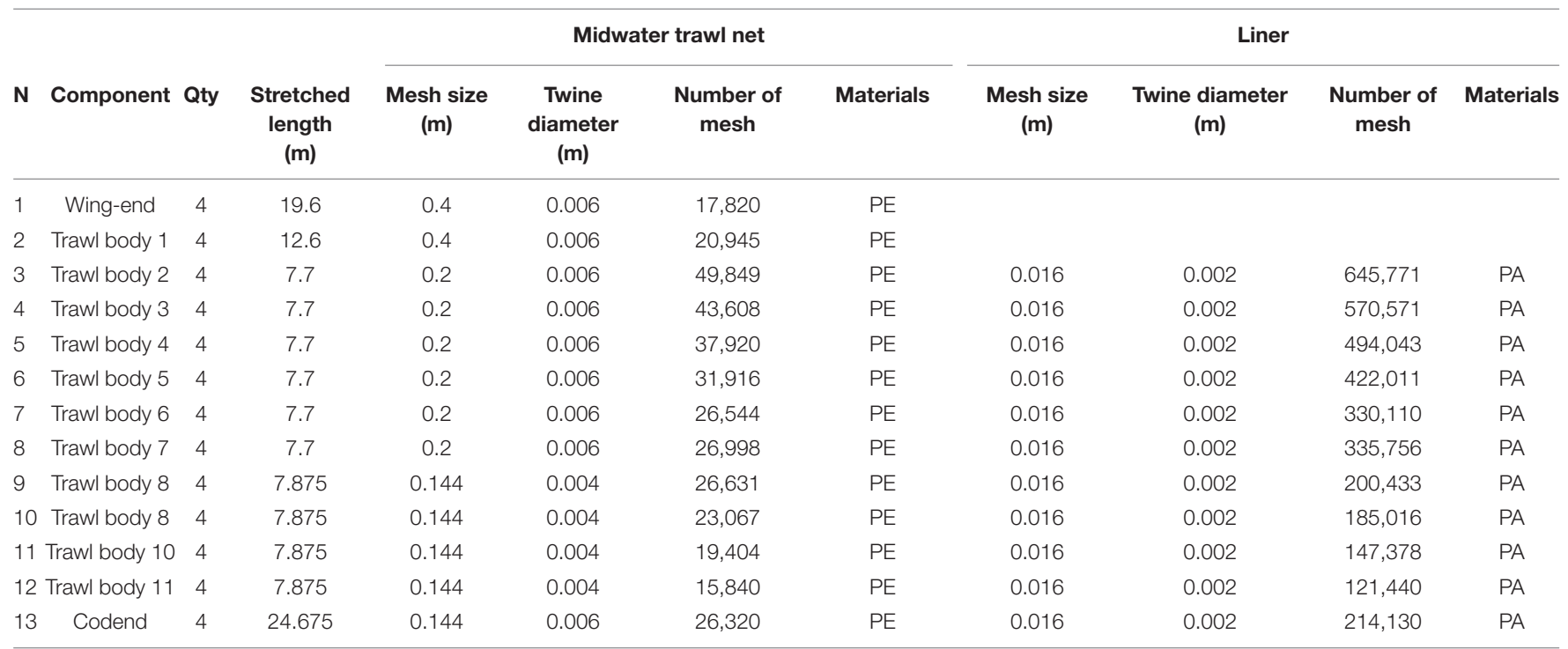

TABLE 2 | Total number of mesh and twine area for trawl net and liner in full scale.

\begin{tabular}{|c|c|c|c|}
\hline Percentage of in liner length (\%) & $\begin{array}{l}\text { Number of mesh } \\
\text { on the trawl }\end{array}$ & $\begin{array}{l}\text { Twine area of } \\
\text { liner }\left(\mathrm{m}^{2}\right)\end{array}$ & $\begin{array}{l}\text { Total twine area of the trawl } \\
\text { including liner }\left(\mathrm{m}^{2}\right)\end{array}$ \\
\hline Trawl with $100 \%$ liner & $4,033,524$ & 234.67 & $1,084.48$ \\
\hline Trawl with $50 \%$ liner & $1,571,017$ & 77.1 & 926.88 \\
\hline Trawl without liner & 366,862 & 0 & 849.82 \\
\hline
\end{tabular}




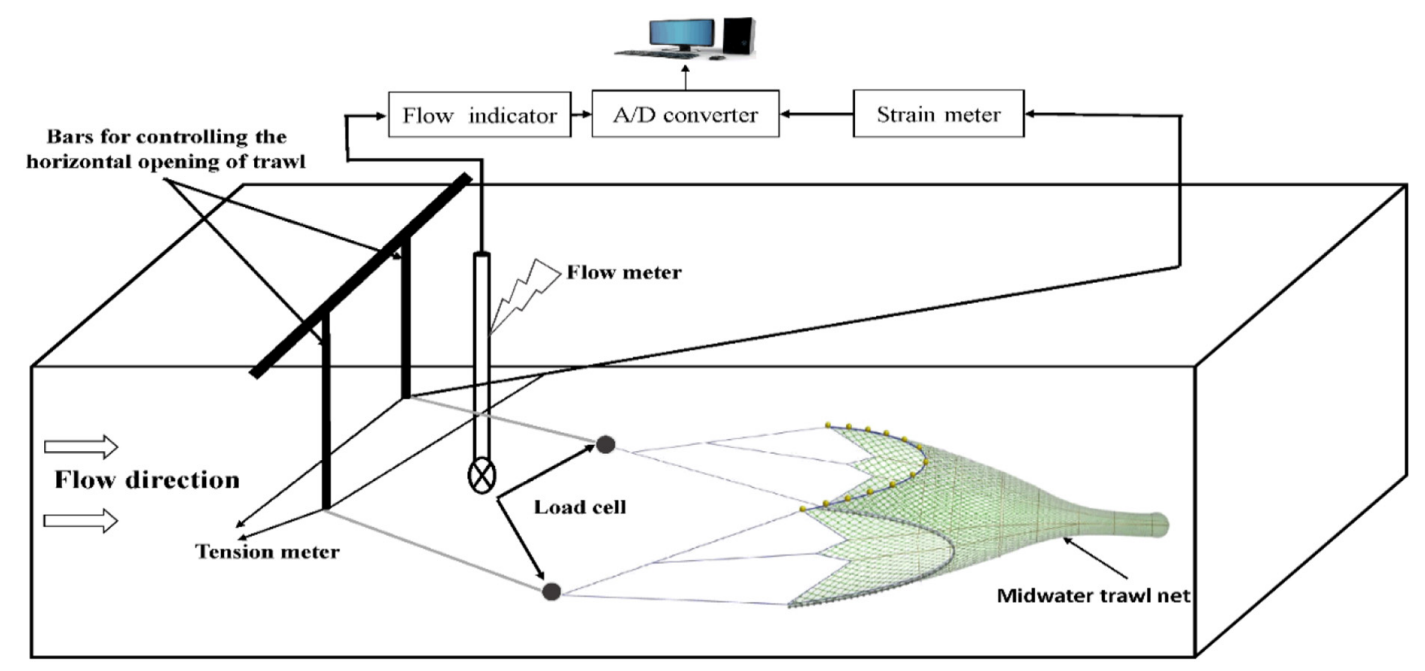

FIGURE 2 | Schematic diagram of experimental setup and apparatus for midwater trawl testing.

trawl net at the mouth was $300 \mathrm{~m}$, the trawl length was $132.8 \mathrm{~m}$, the headline length was $55.38 \mathrm{~m}$, and the fishing line length was $54.88 \mathrm{~m}$. The trawl was constructed from 0.006 and $0.004 \mathrm{~m}$ diameter polyethylene (PE) twine varying in mesh size from $0.4 \mathrm{~m}$ in the wing and the first body section to $0.2 \mathrm{~m}$ in second to seventh body sections, and $0.144 \mathrm{~m}$ in the remaining trawl body sections and the codend (Table 1). The liner was constructed using polyamide (PA) material, with a mesh size of $0.016 \mathrm{~m}$ and a twine diameter of $0.002 \mathrm{~m}$. The vertical opening was ensured by floats distributed on the headline and providing a total buoyancy of $21,187.76 \mathrm{~kg}$, and by the chains weighing $300 \mathrm{~kg}$ on the fishing line and two $300 \mathrm{~kg}$ weights attached to each wing end. Overall, four net models were constructed on $1 / 35$ th scale in length and $1 / 5$ th scale in mesh size and twine diameter based on the fullscale trawl described above. These four trawl models were built with various liner lengths but with the same mesh size, twine diameter, and twine material. However, to ensure the flexibility of the material, the trawl model was built with the Dyneema twine material, which has a small difference in specific density compared with the PE twine material, which is believed to have a very small impact on the test results.

The difference between the four trawl models was based on the coverage of the liner, which was based on the straight length of the trawl body. When the liner was attached to the second section of the trawl body, the trawl model was called "Trawl with $100 \%$ liner"; when it was attached at the fourth section, the trawl model was called "Trawl with 75\% liner"; when it was attached at the seventh section, the trawl model was called "Trawl with 50\% liner"; and the unlined trawl net was called "Trawl without liner."

Twine area $S$ was calculated using the following equation:

$$
S=4 d l N
$$

where $d$ is twine diameter; $l$ is the bar length; and $N$ is the number of mesh in the trawl. The resulting twine areas of the model trawl and liner are shown in Table 2.

\section{Experimental Process in the Flume Tank}

A linear scale of $1 / 35$ was selected as the best balance between the limitations of the test facility (i.e., flume tank size), objectives of the test program, and the ability to extrapolate model results to full-scale performance (Winger et al., 2006). The scale model was built in such a way as to approach the geometric, kinematic, dynamic, and force law of full-scale trawls. Thereby, the scaling model was based on the modified Tauti's law developed by $\mathrm{Hu}$ et al. (2001). Furthermore, the linear scale factor used is defined as the quantity in the full-scale trawl divided by the corresponding quantity in the model (Thierry et al., 2020b). The fundamental

TABLE 3 | The range of variables for model net test.

\begin{tabular}{lcc}
\hline Variables & Full-scale levels & Model net levels \\
\hline Towing speeds $(V)$ & 1.5 knots & $0.29 \mathrm{~m} / \mathrm{s}$ \\
$1.75 \mathrm{knots}$ & $0.33 \mathrm{~m} / \mathrm{s}$ \\
2.0 knots & $0.38 \mathrm{~m} / \mathrm{s}$ \\
2.3 knots & $0.43 \mathrm{~m} / \mathrm{s}$ \\
$2.5 \mathrm{knots}$ & $0.47 \mathrm{~m} / \mathrm{s}$ \\
& 3.0 knots & $0.57 \mathrm{~m} / \mathrm{s}$ \\
Heavy bob weights $(W)$ & $3.5 \mathrm{knots}$ & $0.66 \mathrm{~m} / \mathrm{s}$ \\
& $600 \mathrm{~kg}$ & $97.96 \mathrm{~g}$ \\
& $300 \mathrm{~kg}$ & $48.98 \mathrm{~g}$ \\
The ratio of buoyancy to & $0 \mathrm{~kg}$ & $0 \mathrm{~g}$ \\
fishing line weight $(F / G)$ & 7.3 & 7.3 \\
& & \\
& 5.7 & 5.7 \\
Door spread & 4.2 & 4.2 \\
& 2.6 & 2.6 \\
& $41.65 \mathrm{~m}$ & $1.19 \mathrm{~m}$ \\
& $47.60 \mathrm{~m}$ & $1.36 \mathrm{~m}$ \\
& $53.55 \mathrm{~m}$ & $1.70 \mathrm{~m}$ \\
& $59.50 \mathrm{~m}$ & $1.85 \mathrm{~m}$
\end{tabular}


modeling rules can be summarized as follows, where $F$ and $M$ are the full-scale and model, respectively:

$$
\text { Lengthscale }: \lambda=\frac{L M}{L F}
$$

$$
\text { Meshsizeortwinediameterscale }: \lambda^{\prime}=\frac{a_{M}}{a_{F}}=\frac{d_{M}}{d_{F}}
$$

$$
\begin{aligned}
& \text { Speedscale }: \frac{V_{M}}{V_{F}}=\left(\lambda^{\prime n} \lambda\right)^{\frac{1}{2-n}} \\
& W=\frac{\rho_{s M-\rho_{M}}}{\rho_{s F}-\rho_{F}} \\
& \text { Forcescale }: F_{F}=\frac{F_{M}}{\lambda^{\prime} W \lambda^{2}}
\end{aligned}
$$

where $L, a, d, F, \rho_{s} \rho$, and $V$ are the total stretched length, mesh size, twine diameter, force, material density, water density, and towing speed, respectively, and $n$ represents the exponent of the function $C d=k R e^{-n}$ referring to the study of $\mathrm{Hu}$ et al. (2001). In this function, $C d$ is the drag coefficient, $k$ is a function due to the mesh solidity ratio, and $R e$ is the Reynolds number. In this study, $n$ is assumed to be 0.15 for a midwater trawl net according to Hu et al. (2001). The density of water in the flume tank and that in full-scale were $999.8 \mathrm{~kg} / \mathrm{m}^{3}$. The twine material densities were assumed to be 900,970 , and $1,150 \mathrm{~kg} / \mathrm{m}^{3}$ for the PE, Dyneema, and $\mathrm{PA}$, respectively.

Flume tank experiments were carried out in the flume tank at the Tokyo University of Marine Sciences and Technology (TUMSAT). The dimension of the test section of the tank was $9.0 \mathrm{~m}$ in length, $2.2 \mathrm{~m}$ in width, and $1.6 \mathrm{~m}$ in depth containing $\sim 150$ tons of fresh water. The flow was circulated with four contra-rotating impellers via constant-speed hydraulic delivery pumps with a diameter of $1.6 \mathrm{~m}$. The flow speed varied from 0.1 to $2.0 \mathrm{~m} / \mathrm{s}$, the acceleration varied from 0.01 to $0.05 \mathrm{~m} / \mathrm{s}^{2}$, and the reciprocating oscillation flow of velocity amplitude was \pm $0.5 \mathrm{~m} / \mathrm{s}$ (Hu et al., 2004). The side and bottom viewing window of the flume tank allows users to observe the behavior of the trawl net during experiments and record video. The experiments were carried out in the flume tank by directly connecting the bridles of the trawl to two bars connected to the masts of the flume tank (tension meters) (Figure 2). The trawl model connection point contains a load cell so that the frame-line tension at all
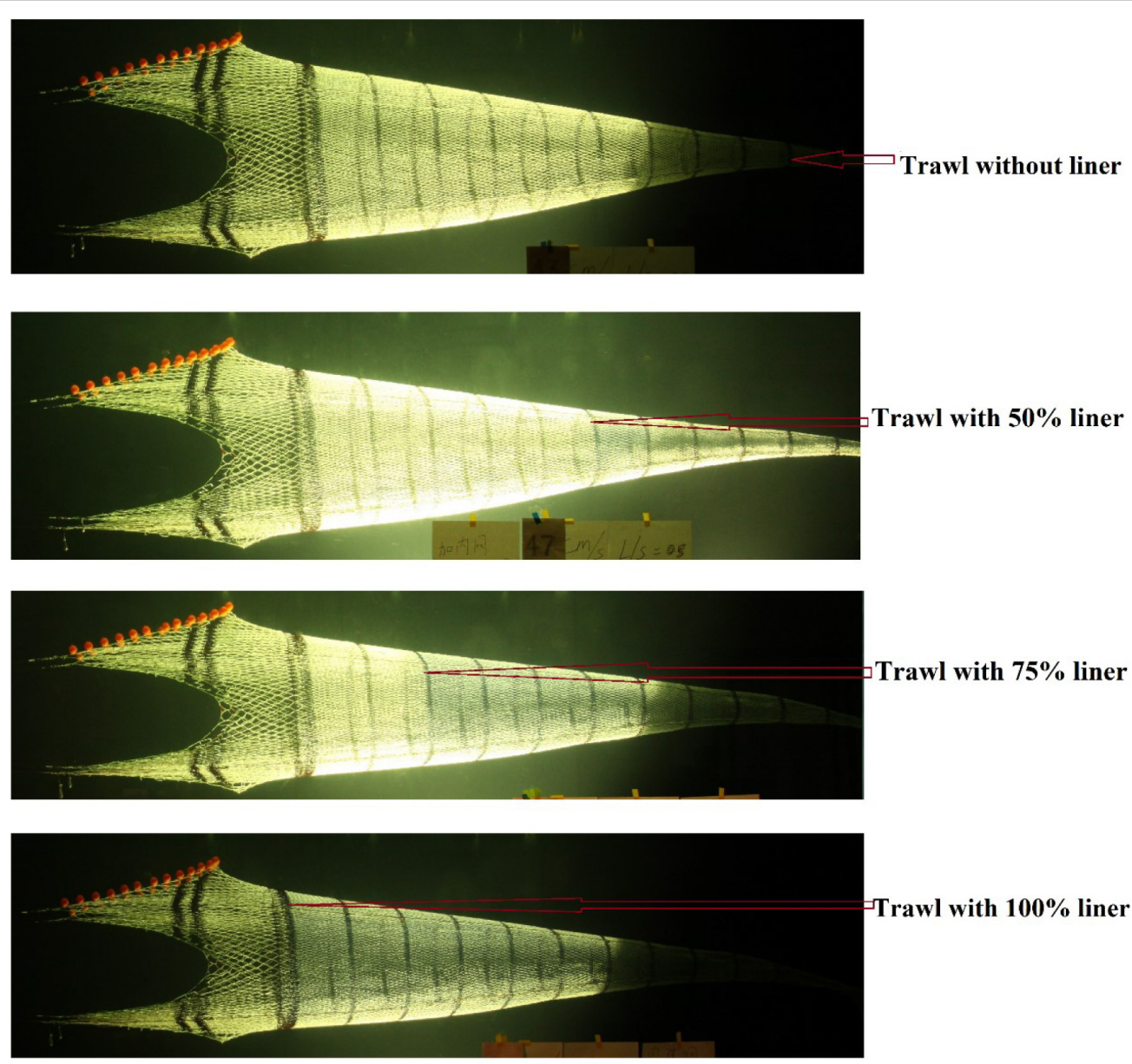

FIGURE 3 | Side views of the midwater trawl net in the flume tank. 
connection points can be measured for each case. This load cell was A3064 manufactured by Electronic Industrial Co., Ltd., with a maximum capacity of $10 \mathrm{~kg}$. The measurements were carried out at seven different towing speeds, five different door spreads, three different heavy bob weights, and at four ratios of buoyancy to the fishing line $(F / G)$ (Table 3). During the measurements, the flow velocity was measured using a propeller tachometer located at $1.2 \mathrm{~m}$ in front of the trawl mouth. As shown in Figure 3, the model trawl located at the middle of the flume tank was free to move in the water flow.

To obtain the data on the geometrical shape of the model nets, cameras were positioned at the side and bottom of the flume tank, respectively. Thus, the estimated engineering performance of the model nets (e.g., wing-end spread, net mouth opening, bridle tension, and codend opening) for each experimental combination of treatments were measured and recorded using the existing optical and data acquisition systems within the flume tank.

\section{Data Processing and Analysis}

The geometrical shape of each trawl net was obtained using a series of images selected from the recorded video footages using digitizing software (GetData graph digitizer) to extract the coordinates of characteristic points of the model trawl based on a plane-coordinate system. After the extraction of the different point coordinates, Matlab software was used to represent the different shapes of the four trawls.

The estimation of the in-pull force $\left(F_{i n-p}\right)$, in order to predict the size of the trawl door for each trawl, was obtained by the following equation (Thierry et al., 2020a):

$$
\begin{gathered}
F_{\text {in }-p}=\frac{T \sin \theta}{2} \\
\text { With } \operatorname{Sin} \theta=\frac{\text { Door spread }-W s}{2^{*} \text { Bridle length }}
\end{gathered}
$$

where $T$ is the bridle tension, $\theta$ is the bridle angle, the bridle length is equal to $1.8 \mathrm{~m}$ in the model test, and $W s$ is the wing-end spread measured during the experiments for each towing speed and each door spread.

Energy efficiency is an important element that can be used to evaluate the engineering performance of the trawl net. The coefficient of energy consumption $\left(C_{\text {enf }}\right)$ represents the energy consumed by the midwater trawl for unit volume of water

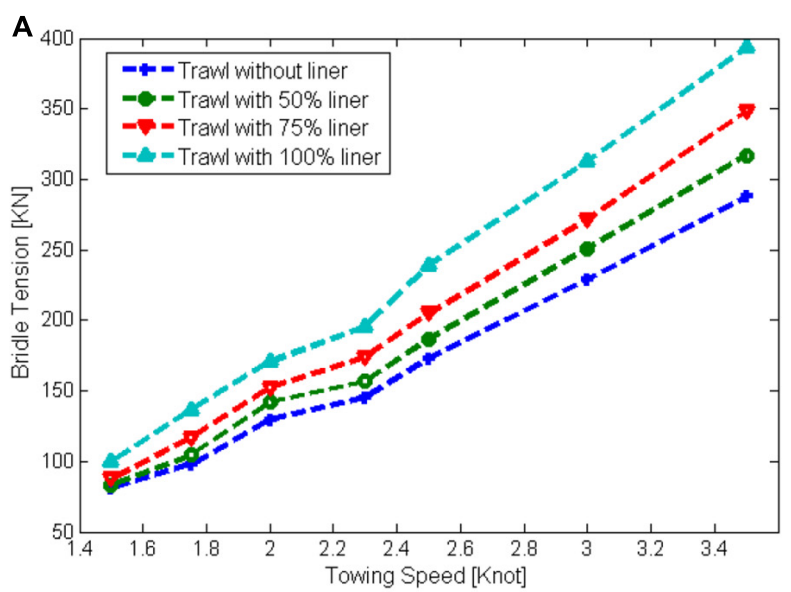

C

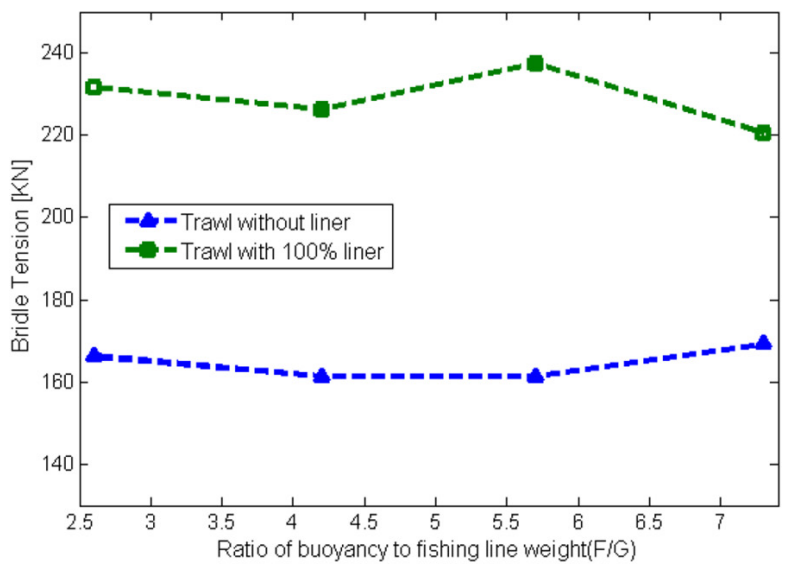

B

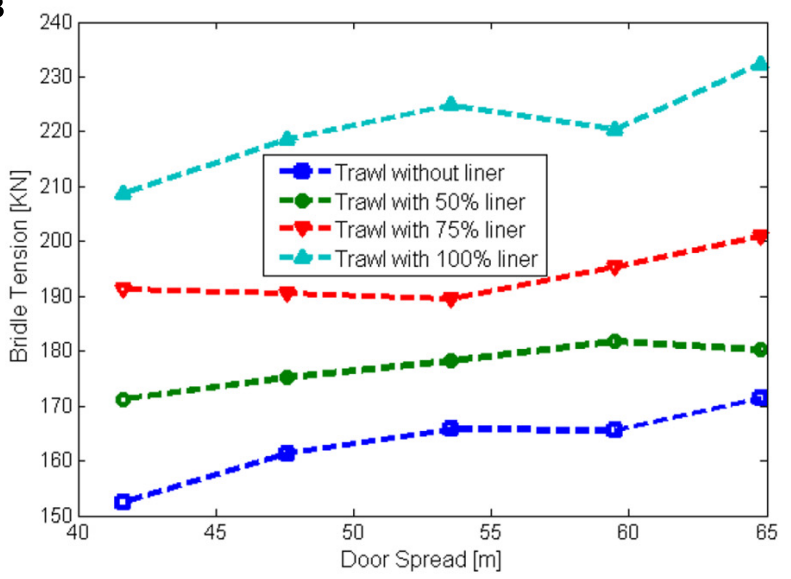

D

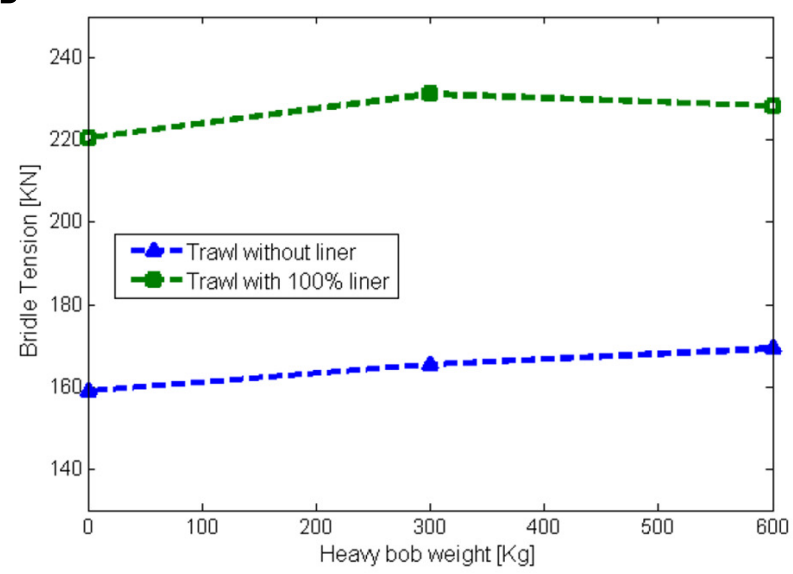

FIGURE 4 | Bridle tension of the different trawls about the (A) towing speed, (B) door spread, (C) ratio of buoyancy to $F / G$, and (D) heavy bob weight: current data estimated with $95 \%$ confidence intervals from the statistical analysis. 
filtered during the fishing operation and was calculated using the following formula (Xu, 2004):

$$
C_{\mathrm{enf}}=\frac{3.472 * F d}{H * W s}
$$

where $F d$ is the drag force of the trawl net system, $H$ is the vertical opening of the trawl mouth, and $W s$ is the wing-end spread. In this study, $F d$ is calculated using the following equation:

$$
F d=T \cos \theta
$$

Analysis of covariance (ANCOVA) and generalized linear model (GLM) were used to analyze the data regarding the bridle tension, in-pull force, the coefficient of energy consumption, and trawl geometry obtained from each midwater trawl with different configurations to investigate the effects of liner length (twine area) on the predicted full-scale performance of krill trawl. All statistical procedures were performed using the IBM SPSS Statistics software.

\section{RESULTS}

\section{Effect of Liner on the Hydrodynamic Performance}

As the towing speed and door spread increase, the bridle tension gradually increases (Figures 4A,B). The bridle tension of the trawl with $100 \%$ liner had the greatest increase compared with those of other trawls for all towing speeds and door spreads. The mean bridle tension of this trawl is $26.16,19.78$, and $12.44 \%$ greater than those of trawl net without, with 50 , and $75 \%$ liner, respectively, across all speeds and door spreads. Clearly, the trawls without, with 50, and 75\% liner were designed to contain a small amount of twine in the main body compared with the trawl net with 100\% liner and those used in the Antarctic krill fisheries. Twine area of trawl net without liner is 11.01, 19.31, and 30.69\% less than those of trawls with 50,75 , and $100 \%$ liner, respectively (Table 2). While the bridle tension of the trawl with $100 \%$ liner had greater fluctuations with an increasing ratio of buoyancy to fishing line weight $(F / G)$ compared with that without liner, the bridle tension of both nets had less changes with the increase in heavy bob weight (Figures 4C,D). The mean variations in
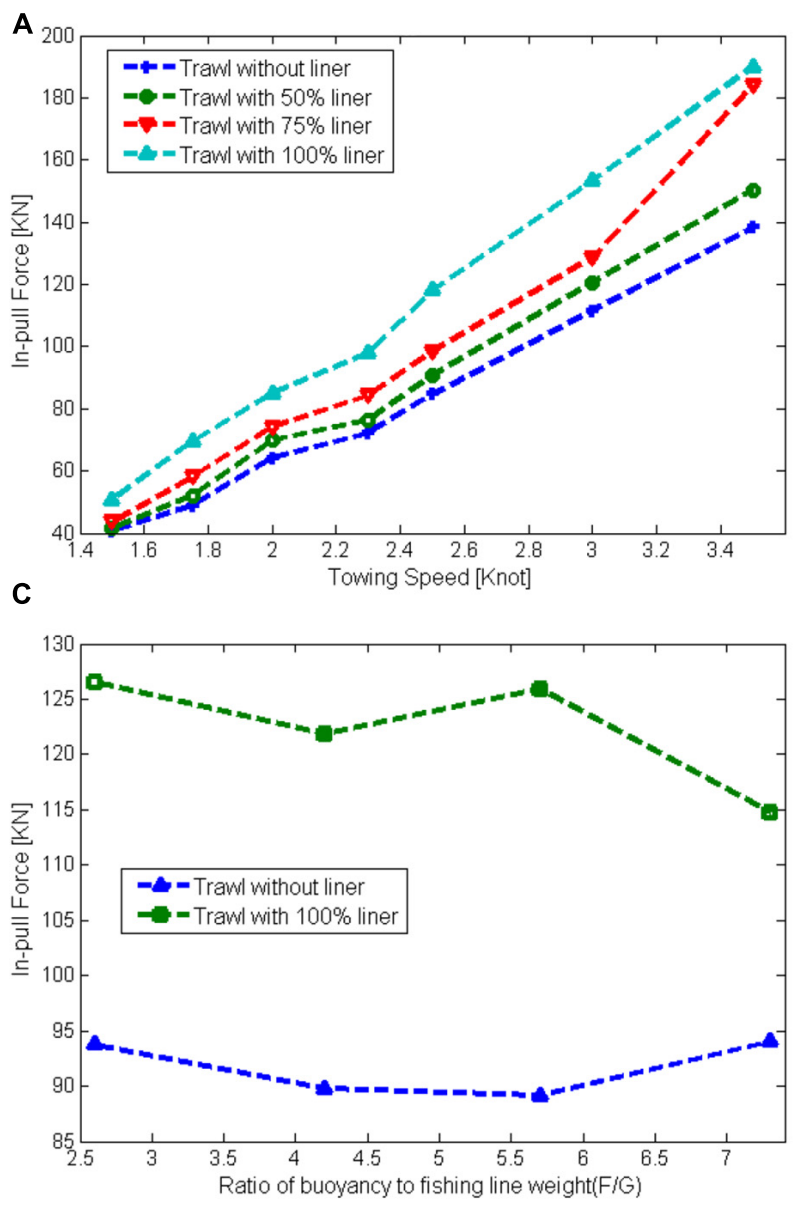
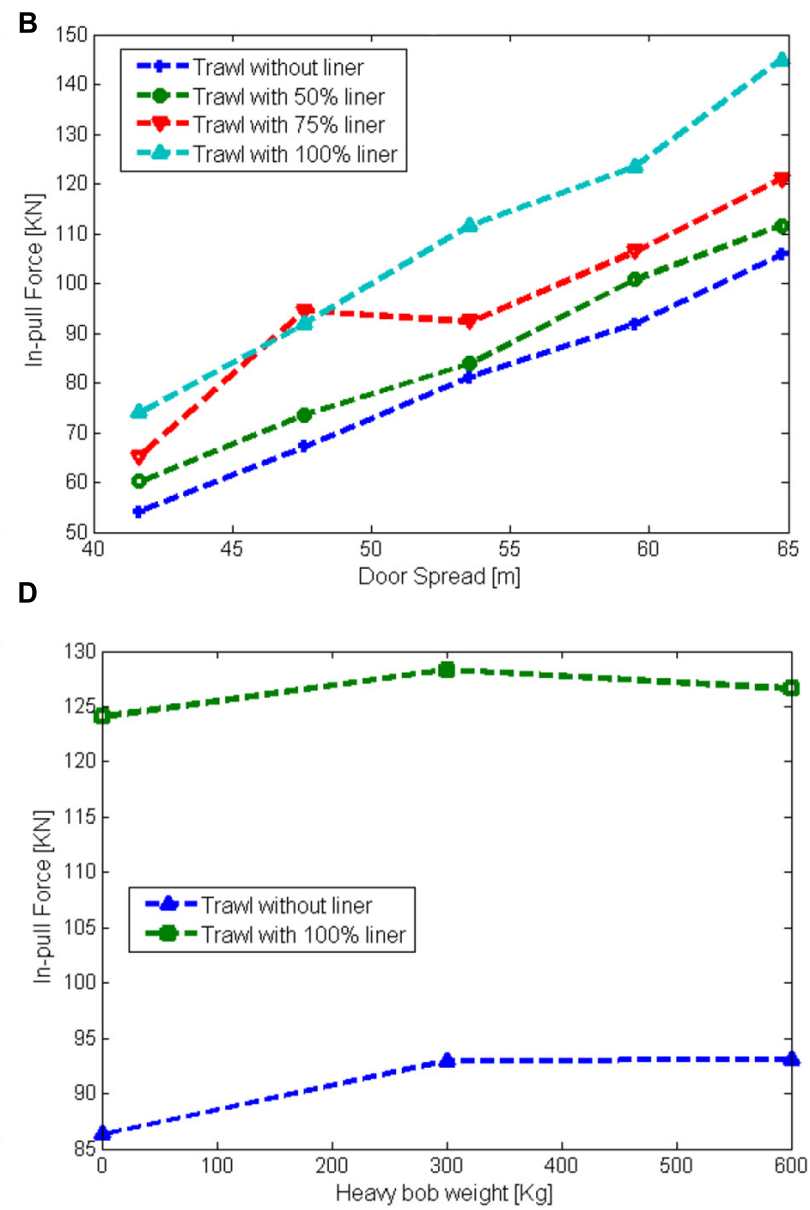

FIGURE 5 | The in-pull force of the different trawls about the (A) towing speed, (B) door spread, (C) ratio of buoyancy to fishing line weight (F/G), and (D) heavy bob weight: current data estimated with $95 \%$ confidence intervals from the statistical analysis. 
bridle tension were $74.84 \%$ between the low and high speeds, $11.01 \%$ between the low and high door spreads, $7.15 \%$ between the low and high $F / G$ values, and $6.09 \%$ between the low and high heavy bob weights for all the four trawls and their differences are statistically significant $(p<0.05)$. In general, $F / G$ and the heavy bob weights have less influences on the bridle tension, while the towing speed and the door spread have greater influences on the bridle tension.

Figures 5A,B show that the in-pull force of the four trawls increases as the towing speed and door spread increase $(p<0.05)$. Increases in liner length and twine area lead to an increase in the in-pull force; the trawl with $100 \%$ liner was $26.66,21.22$, and $12.20 \%$ greater in the in-pull force than those of trawl net without liner, with 50\% liner, and with $75 \%$ liner, respectively $(p<0.05)$. The value of in-pull forces is directly related to the size (surface area) of otter boards. Therefore, trawls without the liner and with $50 \%$ liner would require similar size otter boards that are about three-quarters of the size of those required for the trawl with $100 \%$ liner. The size of otter boards required for the trawl with $75 \%$ liner would be the seventh eighth of those required by the trawl with $100 \%$ liner.
The in-pull force of both the trawl without the liner and the trawl with $100 \%$ liner decreased gradually with the increase in $F / G$ (Figure 5C) but almost no change with the increase in heavy bob weight (Figure 5D).

The coefficient of the energy consumption increased as the towing speed increased for all trawls tested (Figure 6A) but decreased slightly as the door spread increased for all trawls except for the trawl without liner (Figure 6B). The difference in coefficient of energy consumption is $16.56 \%$ between trawls without the liner and that with $50 \%$ liner, $9.45 \%$ between trawls with 50 and $75 \%$ liner, and $17.98 \%$ between trawls with 75 and $100 \%$ liner $(p<0.05)$. The results indicate that using the trawl with 50 and $75 \%$ liner would reduce the fuel consumption by about 25.73 and $17.98 \%$, respectively, compared with the traditional trawl (the trawl with $100 \%$ liner) as used in the Antarctic krill fisheries $(p<0.05)$.

In addition, the coefficient of the energy consumption slightly increases as the ratio of buoyancy to $F / G$ increases for the trawl without liner, while one of the trawls with $100 \%$ liner decreases as $F / G>4.2$ and $F / G>5.7$, then increases as $4.2<F / G<5.7$. Moreover, the coefficient of the energy consumption for the trawl
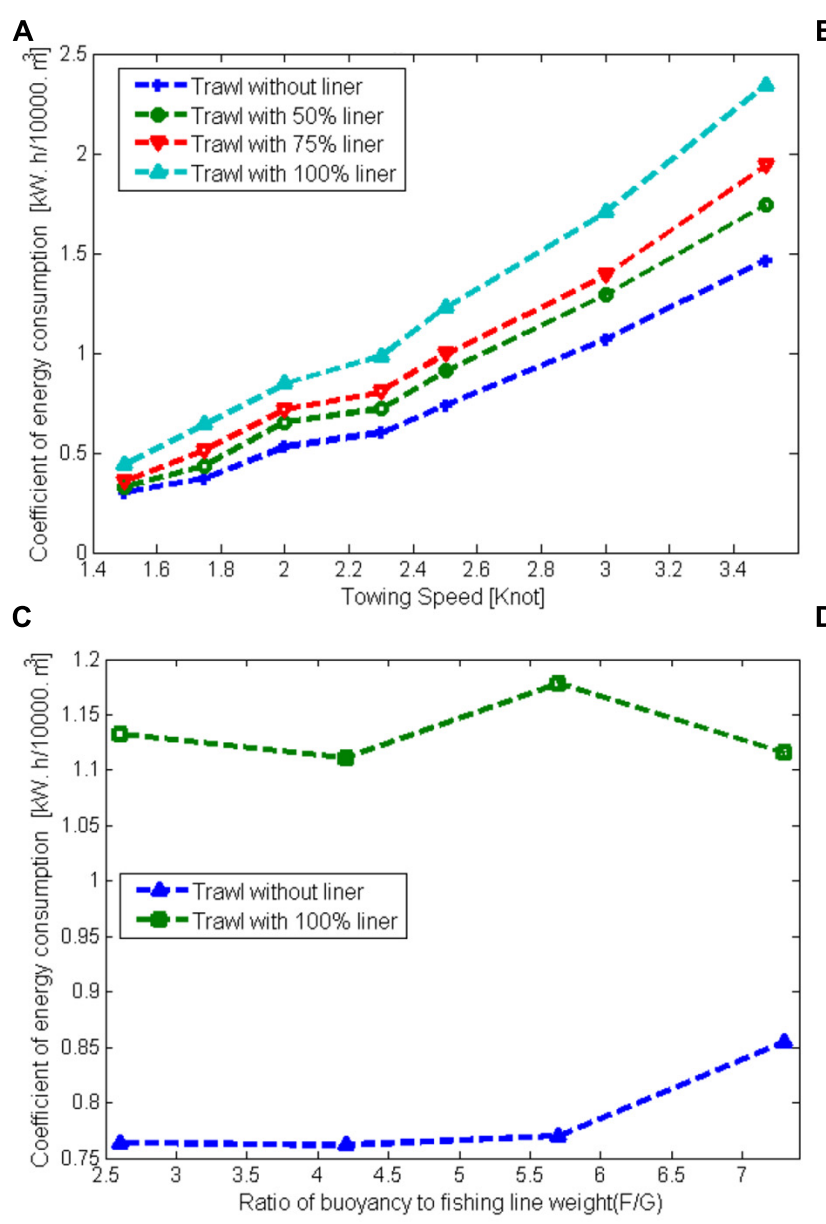
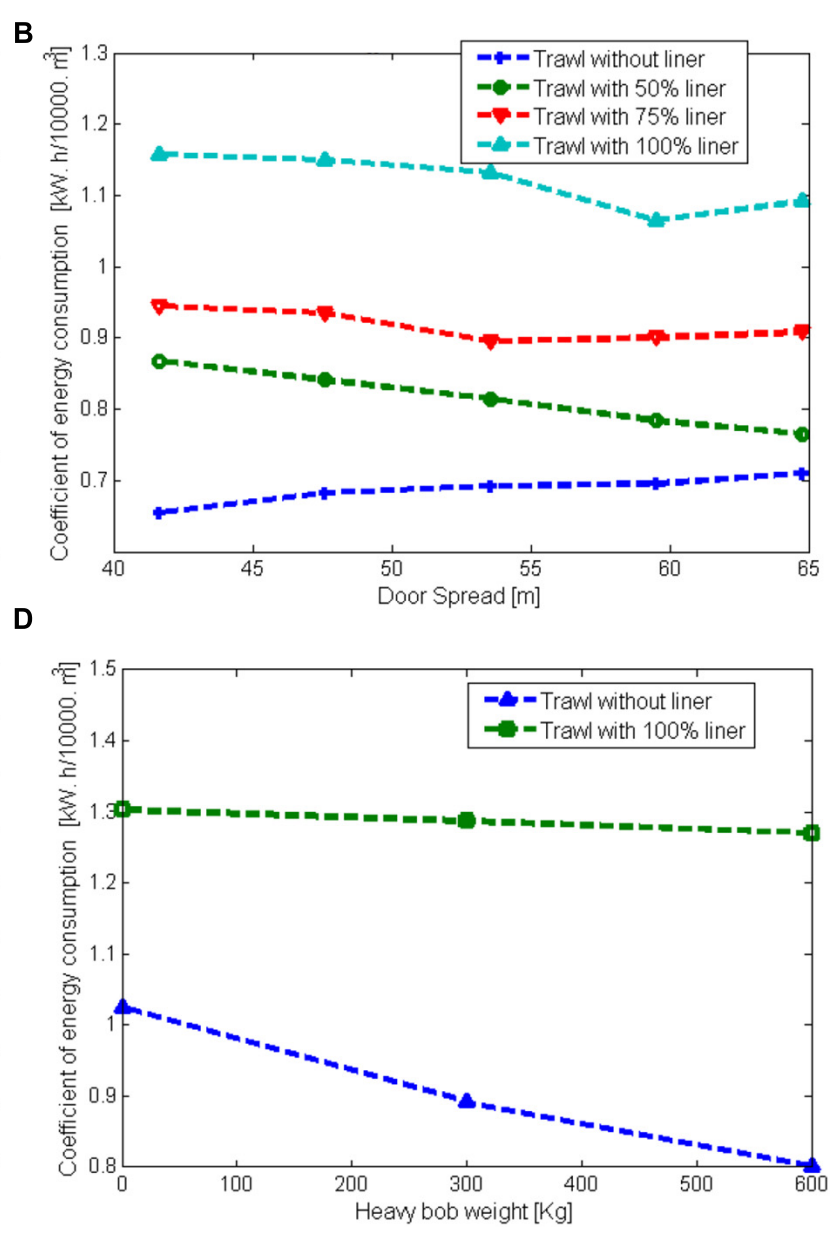

FIGURE 6 | Coefficient of energy consumption of the different trawls about the (A) towing speed, (B) door spread, (C) ratio of buoyancy to $F / G$, and (D) heavy bob weight: current data estimated with $95 \%$ confidence intervals from the statistical analysis. 
without liner decreases as the heavy bob weight increases, while the one of the trawls with $100 \%$ liner has the smaller changes with the increase in heavy bob weight (Figures 6C,D).

\section{Effect of Liner on the Trawl Opening}

The horizontal opening of the net mouth increased with the increase in towing speed, door spread, and the ratio of buoyancy to $F / G$, but it decreased with the increase in heavy bob weight for all four trawls (Figure 7). The variations in the horizontal mouth opening of all trawls were less than $7.34,11.45,3.27$, and $7.91 \%$ between different towing speeds, door spreads, $F / G$, and heavy bob weight, respectively $(p<0.05)$. The mean horizontal mouth opening of trawl with $100 \%$ liner was $3.72,1.18$, and $4.92 \%$ lower than that of trawls without liner, with 50\% liner, and 75\% liner, respectively $(p<0.05)$. The towing speed and the door spread explained $97 \%$ of the variation in the horizontal opening of the net mouth.

As shown in Figure 8, the vertical opening of the net mouth decreased with the increase in towing speed, door spread, and $F / G$ but increased with the increase in heavy bob weight. The variations in vertical mouth opening of all trawls were less than $12.11,5.85,4.95$, and $6.15 \%$ between different towing speeds, door spreads, $F / G$, and heavy bob weight, respectively $(p<0.05)$. The vertical mouth opening of the trawl with $100 \%$ liner was 9.33 ,
5.38 , and $2.63 \%$ lower than that of the trawls without liner, with $50 \%$ liner, and with $75 \%$ liner, respectively $(p<0.05)$.

The wing-end spread was strongly affected by towing speed and door spread, and the ratio of buoyancy to $F / G$ (Figure 9). The wing-end spread of all trawls increased with the increases in towing speed, door spread, and the ratio of buoyancy to $F / G$ but remained unchanged with the changes in heavy bob weight (Figure 9D). On average, trawl without liner had a higher wingend spread, which was $5.72,4.74$, and $8.28 \%$ greater than those of trawls with 50, 75, and 100\% liner, respectively $(p<0.05)$.

\section{Effect of Liner on the Mouth Net Area and Swept Area}

The net mouth area, which is determined by the vertical mouth opening and horizontal mouth opening, decreased as the towing speed and the ratio of buoyancy to $F / G$ increased but increased with the increasing door spread and heavy bob weight for all the four trawls (Figure 10). Decreases in liner length led to increases in the net mouth area. The maximum net mouth area was obtained by the trawl without liner, which was $4.52,8.04$, and $11.84 \%$ greater than those of trawls with 50,75 , and $100 \%$ liner, respectively $(p<0.05)$. Towing speed, door spread, $F / G$, heavy bob weight, and net mouth opening

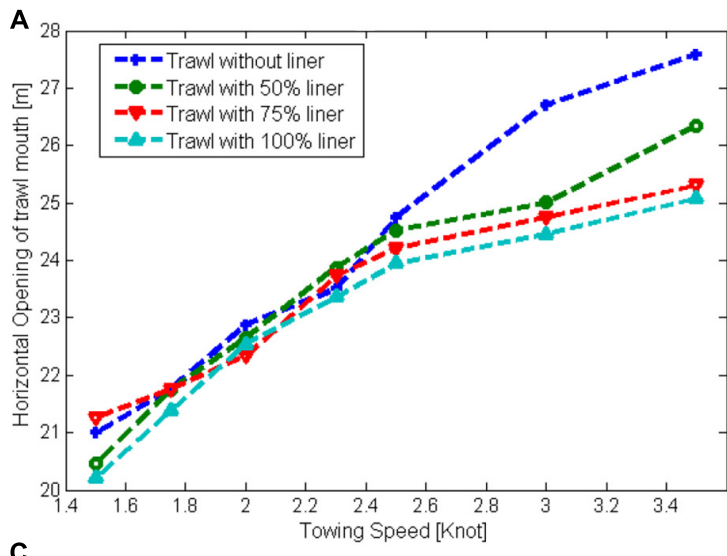

C

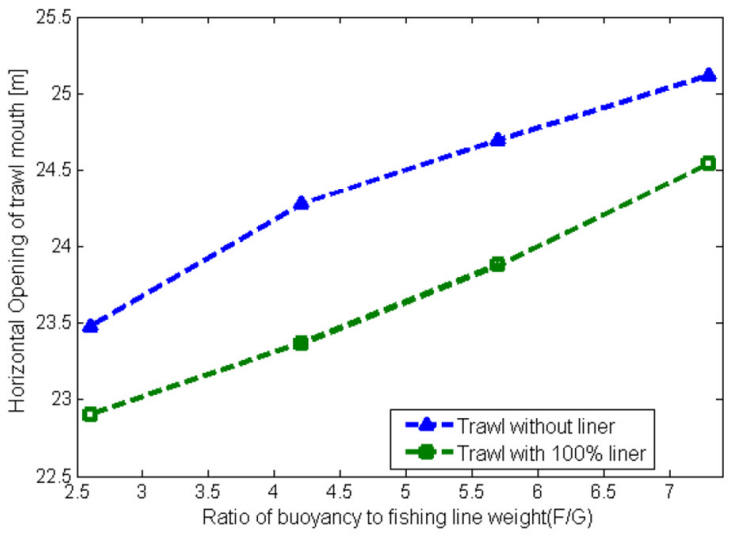

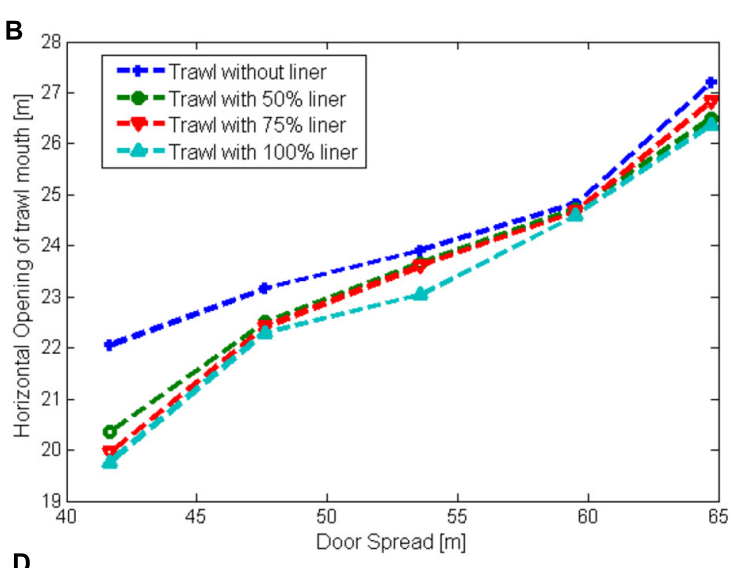

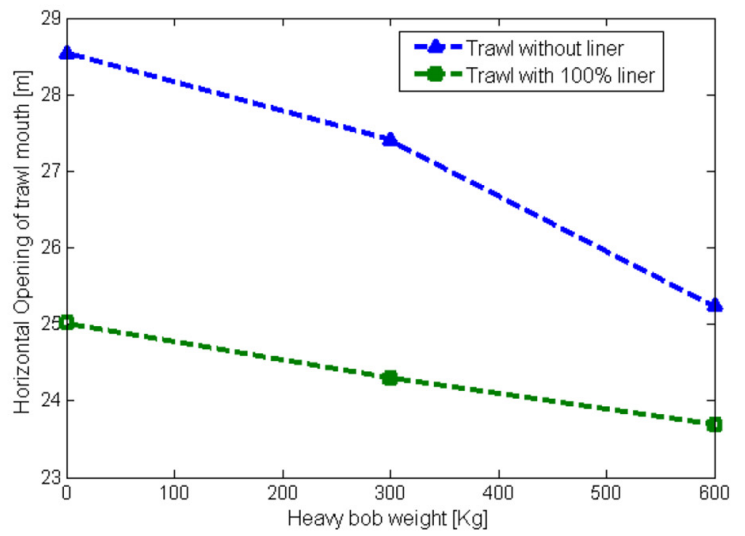

FIGURE 7 | The horizontal diameter of the elliptical trawl net mouth shape of different trawls about the (A) towing speed, (B) door spread, (C) ratio of buoyancy to F/G, and (D) heavy bob weight: current data estimated with 95\% confidence intervals from the statistical analysis. 

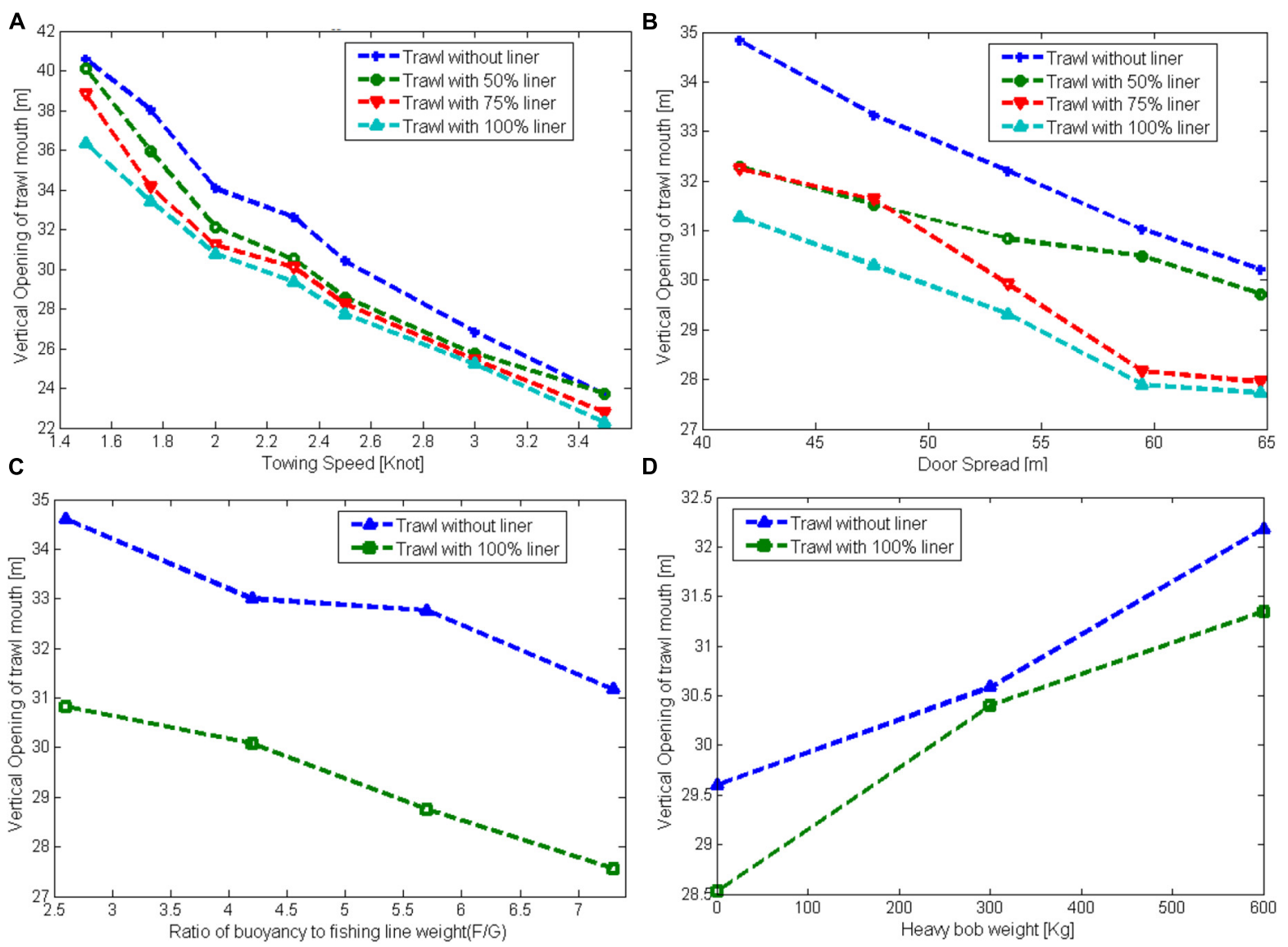

FIGURE 8 | The vertical diameter of the elliptical trawl net mouth shape of different trawls about the (A) towing speed, (B) door spread, (C) ratio of buoyancy to F/G, and (D) heavy bob weight: current data estimated with 95\% confidence intervals from the statistical analysis.

explained $99.97 \%$ of the variation in the net mouth area $(p<0.05)$.

The swept area can best reflect the spread performance of the trawl, which is determined by headline height (vertical opening of the net mouth) and wing-end spread. Figure 11 shows that the swept area of the midwater trawl decreased with the towing speed and heavy bob weight but increased with door spread and $F / G$. On average, the swept area of trawl with $100 \%$ liner is $16.76,8.38$, and $6.52 \%$ lower than that of trawl without liner, with $50 \%$ liner, and with $75 \%$ liner, respectively $(p<0.05)$. The statistical analysis indicates that the variation in the swept area of all trawls ranges from 0.74 to $9.44 \%$ between different towing speeds, 0.7 to $5.61 \%$ between different door spreads, 0.41 to $3.27 \%$ between different $F / G$ values, and from 0.57 to $8.65 \%$ between different heavy bob weights $(p<0.05)$.

\section{DISCUSSION}

Changes in the liner trawl length (and resulting changes in the trawl twine area), door spread, heavy bob weight, and $F / G$ may be some of the solutions to improve the engineering performance of midwater trawl with lower energy consumption, higher catch efficiency, and better size selectivity. Catch efficiency for krill is directly related to trawl mouth opening and sweep area, which allow for trawl to sieve a large volume of water. The length of the liner directly relates to the escape of krill through the meshes of the trawl, thus affecting size selectivity and catch retention. This study demonstrates that model tests in the flume tank can be used to predict the full-scale engineering performance of Antarctic krill trawl at the sea, despite the fact that under real fishing conditions, the performance of trawl would likely have greater uncertainties due to variations in oceanographic conditions (Nguyen et al., 2015; Thierry et al., 2021b).

New trawl designs with reduced lengths in the liner exhibited a lower bridle tension (drag) compared with the midwater trawls commonly used in the Antarctic krill fisheries (trawl with 100\% liner). The critical factor that effectively reduced the bridle tension (drag) of the trawls with shortened liner was a reduction in the twine area. The trawls without liner, with 50\% liner, and $75 \%$ liner contained less twine, and thus lower drag, compared with the traditional trawl (trawl with $100 \%$ liner) used in the Chinese krill fisheries. The findings of this study confirmed the trend followed by Wileman and Hansen (1988), Balash et al. (2015), Sterling and Balash (2017), Lee et al. (2018), and Thierry et al. (2020a, 2021a,c), who modified the twine diameter, 


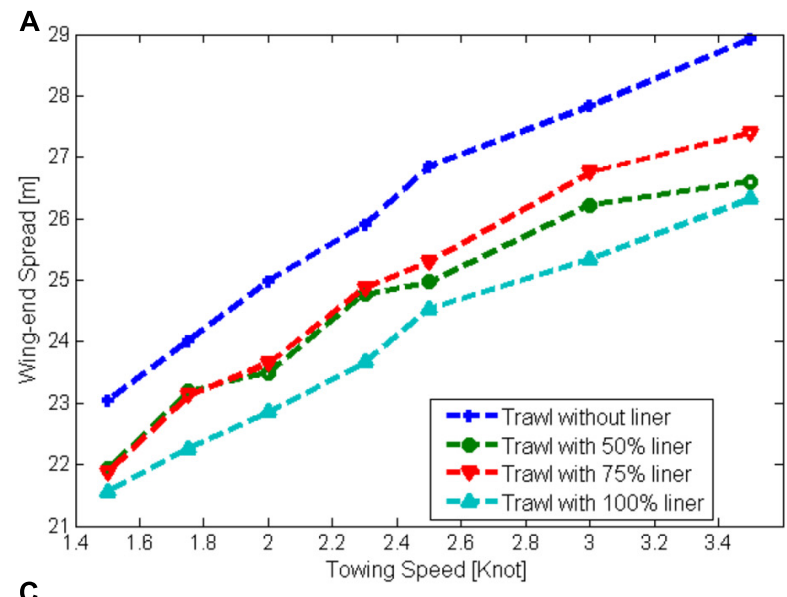

C

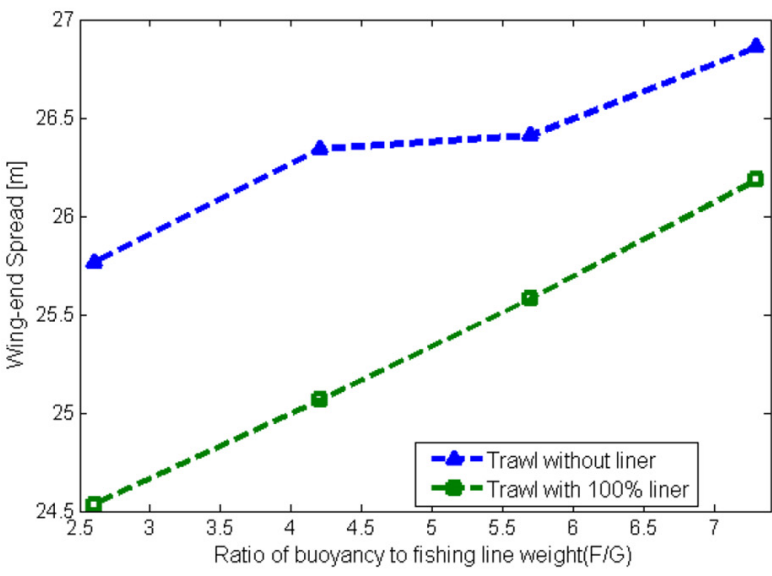

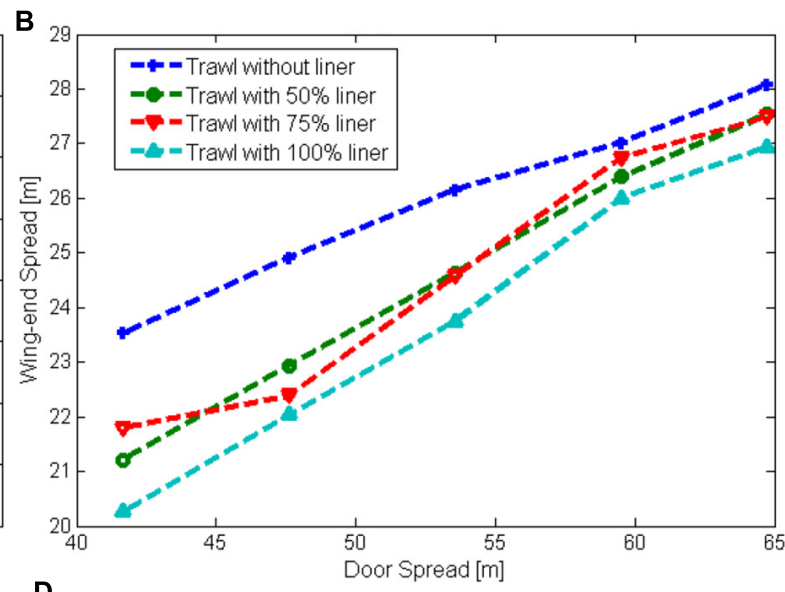

D

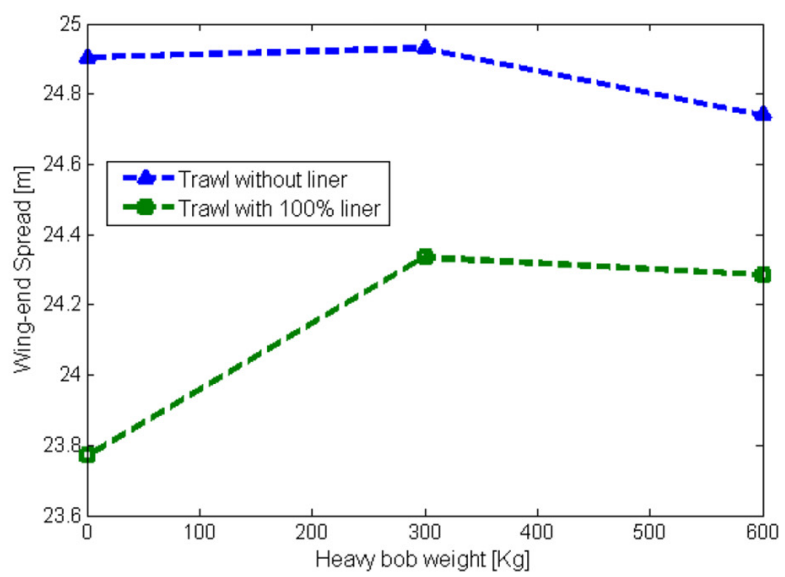

FIGURE 9 | The wing-end spread of different trawls about the (A) towing speed, (B) door spread, (C) ratio of buoyancy to F/G, and (D) heavy bob weight: current data estimated with $95 \%$ confidence intervals from the statistical analysis.

mesh size, and mesh orientation on the trawl body to reduce the twine area and trawl drag. This study combined the impact of liner length, towing speed, door spread, heavy bob weight, and $F / G$ on the hydrodynamic performance of the krill trawl net. The modifications to the krill trawl net in this study reduced the twine area and drag force by 8.6 to $24.49 \%$ than that obtained by Xu et al. (2015) and Feng et al. (2017), who modified the total length of trawl and the net mouth circumference to improve the engineering performance of Antarctic krill trawls.

Lower bridle tensions for all trawl models can be achieved at lower towing speed and door spread, and higher heavy bob weight and the ratio of buoyancy to $F / G$, following similar trends obtained by Feng et al. (2012, 2017), Nguyen et al. (2015), and Li et al. (2017). These findings are very interesting for the Antarctic krill fisheries and have resulted in a recommendation to towing krill trawls at lower towing speed from 2.0 to 2.5 knot, as Antarctic krill have weak swimming ability (Juáres et al., 2018). This will reduce trawl drag by about 23.34 to $42.5 \%$ compared with those towed at higher speeds (3.0-3.5 knot) for the four trawls (Figure 4). However, although the bridle tension increases as the door spread increases for all trawl models tested, the higher door spread (higher horizontal opening of trawl net) increases sweep area, thus higher catch rates. Since the differences in bridle tension between the different door spreads are less than $11.5 \%$, it is beneficial for the vessel to use the maximum door spread, heavy bob weight, and $F / G$ to allow the midwater trawl net to have a very good performance during the trawling.

Reductions in the in-pull force allow the use of the smallsize otter boards, which would lead to the reduction in the drag of the trawl system (Balash et al., 2015; Wan et al., 2019). This study demonstrated that the reduction in liner length and twine area of the trawl nets can lead to the reduction in the in-pull force, thus the size of the otter board of about one-eighth to onequarter compared with the size of otter boards commonly used for the midwater trawl in the Antarctic krill fisheries (Figure 5). This trend was confirmed by Thierry et al. (2020a) who showed that reducing twine diameter and increasing mesh size led to a reduction in twine area, which systematically reduce the in-pull force. However, the results obtained in this study were different from those obtained by Balash et al. (2015) who showed that increasing the twine area resulted in a decrease in the in-pull force. The reason for this difference was the fact that Balash et al. (2015) used square mesh netting on a modified prawn trawl, which is known to produce low drag because it is less affected 
A

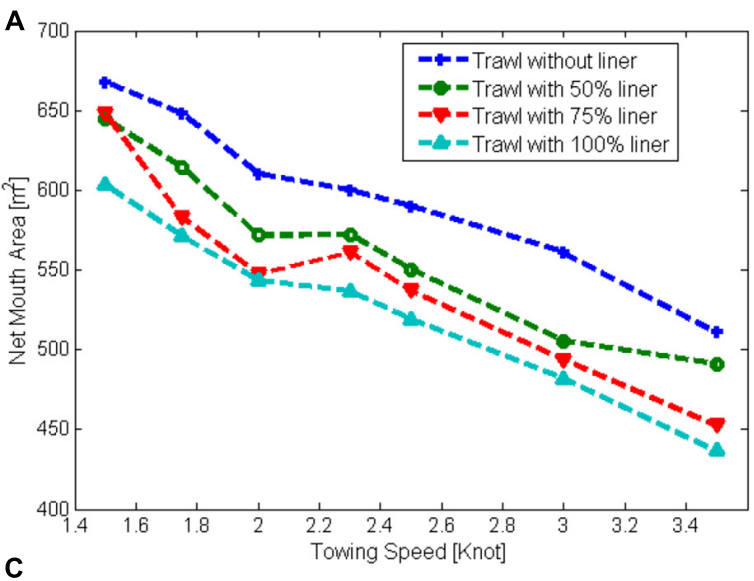

C

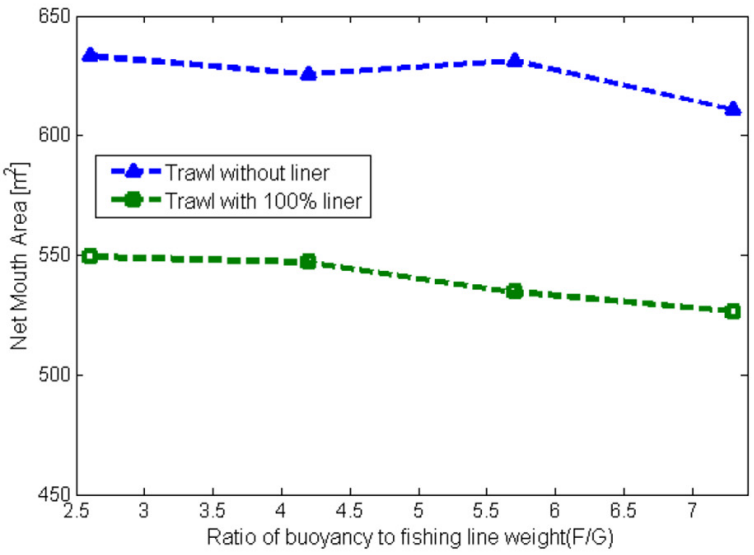

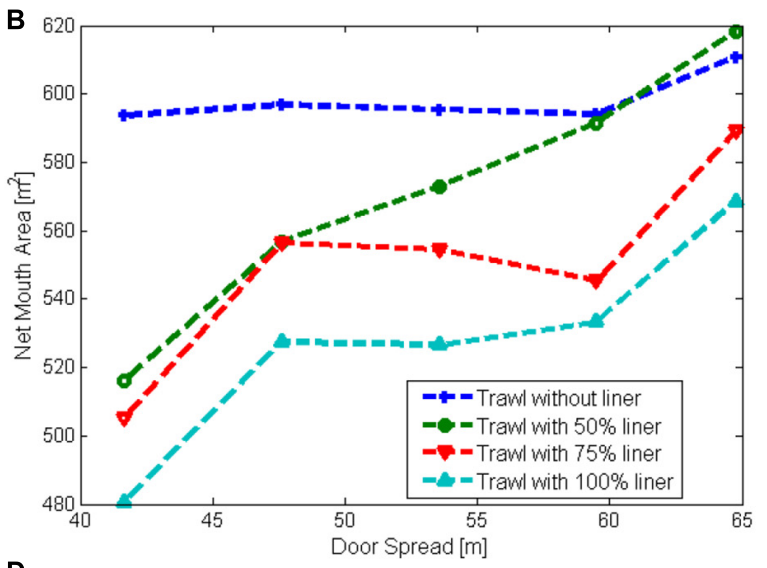

D

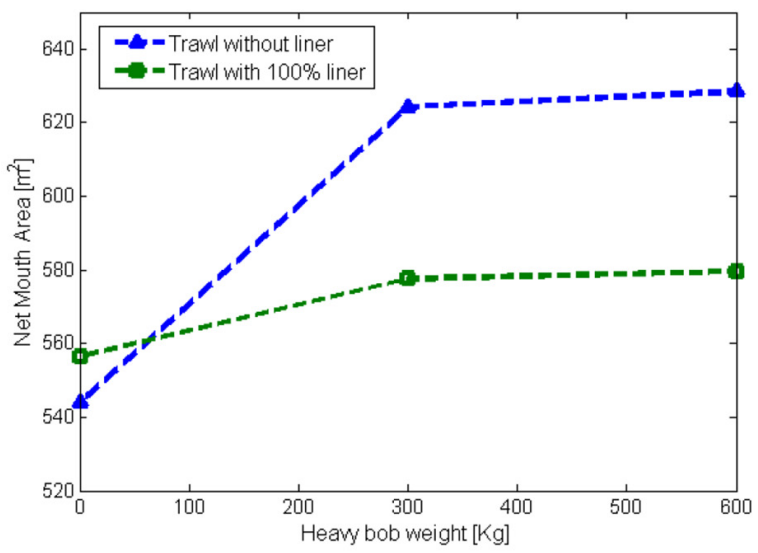

FIGURE 10 | The mouth net area of different trawls about the (A) towing speed, (B) door spread, (C) ratio of buoyancy to F/G, and (D) heavy bob weight: current data estimated with $95 \%$ confidence intervals from the statistical analysis.

by the turbulent flow unlike the diamond mesh (Druault and Germain, 2016). In addition, the smaller in-pull force for all trawls at the required towing speed was found at the lower door spread. However, changes in the heavy bob weight and $F / G$ would not impact the size of otter boards for the Antarctic krill trawl. The size of otter boards is smaller under these conditions than other conditions, and it will be better to choose the door spread from 59.55 to $64.75 \mathrm{~m}$ according to Zhou et al. (2016).

Concerning the coefficient of energy consumption, the trawl net designed without liner, with $50 \%$ liner, and with $75 \%$ liner exhibited a lower energy consumption coefficient than the trawl with $100 \%$ liner. In fact, our results showed that the decreases in twine area gradually increased energy efficiency of the trawl net by 17.98 to $38.03 \%$ on average using the trawl with $50 \%$ liner and with 75\% liner (Figure 6). The tendency of the energy consumption coefficient to increase with the twine area has been recognized by Xu et al. (2015), Feng et al. (2017) and Li et al. (2017). However, we do not recommend a trawl without a liner because it would not likely retain any Antarctic krill due to their small sizes (less than $50 \mathrm{~mm}$ ) (Juáres et al., 2021).

Our results demonstrated that decreases in the liner length would increase trawl net opening. This is because unlined large mesh sections on the mouth area would increase the trawl mouth opening as demonstrated by Sendłak (1998) and Sala et al. (2008). The tested trawls without liner, with 50\% liner, with $75 \%$ liner, and $100 \%$ liner had a vertical opening of $31.5-34 \mathrm{~m}, 29.5-$ $32.5 \mathrm{~m}, 28.9-31.5 \mathrm{~m}$, and $27.6-30.8 \mathrm{~m}$, respectively, at the towing speed required for krill trawling; all meeting the required vertical opening during trawling (between 20 and $30 \mathrm{~m}$ ). It was observed that the vertical and horizontal openings obtained in the study were much greater than those previously obtained by Feng et al. (2017) and Wan et al. (2019) because they focused their studies on the increase in the mouth circumference through the size of the trawl and the towing speed. This study combined many factors to achieve optimal mouth opening to solve the problem of catch efficiency, which is still encountered in the Antarctic krill fisheries (Feng et al., 2012; Xu et al., 2015).

Our results and those previously obtained by Fiorentini et al. (2004), Nguyen et al. (2015), Xu et al. (2015), Feng et al. (2017), and Thierry et al. (2020a,b) demonstrated that the wing-end spread depends on the factors such as towing speed and door spread. Thus, it was found that the door spread and the towing speed explained about $97 \%$ of the variation in the wing-end spread, the remaining $3 \%$ can only be explained by the liner design, heavy bob weight, and $F / G$. As the trawls with 50 and $75 \%$ liner exhibited 

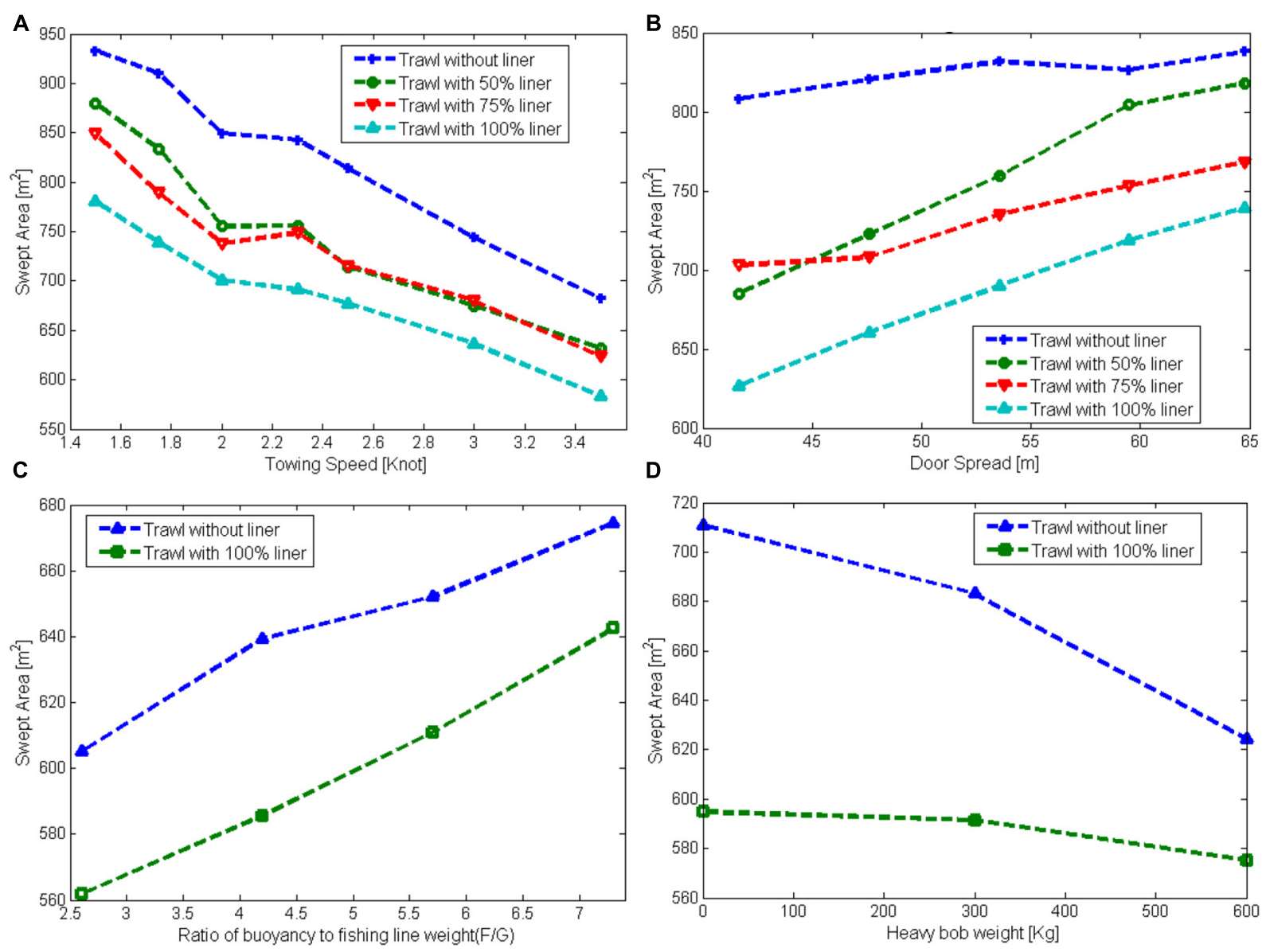

FIGURE 11 | The swept area of different trawls about the (A) towing speed, (B) door spread, (C) ratio of buoyancy to F/G, and (D) heavy bob weight: current data estimated with 95\% confidence intervals from the statistical analysis.

a higher wing-end spread than that of the trawl with $100 \%$ liner, we, therefore, conclude that reducing the liner length and using a greater door spread will be beneficial for increasing the horizontal opening of the trawl, thus increasing catch rates.

Regarding the trawl swept area, this study and Wileman and Hansen (1988), Sala et al. (2008), Xu et al. (2015), and Li et al. (2017) demonstrated that the trawl mouth opening with the towing speed, door spread, heavy bob weight, and $F / G$ greatly affected the midwater trawl swept area. Thus, the more the liner length decrease, the more the mesh size on the trawl body increases and the more the mouth area and sweep area increase. Notably, the swept area has a great interest in the effectiveness of the trawl in targeting large krill schools, thus improving the trawl catchability. It can be demonstrated by the fact that the trawls with 50 and $75 \%$ liner, which can be used in the Antarctic krill fisheries have a swept area of approximately $8 \%$ greater than that of the traditional trawl that is currently used by the Antarctic krill fishery (trawl with $100 \%$ liner).

Results from this study can also be used to improve the size selectivity of the midwater trawl used in the Antarctic krill fisheries. In fact, according to Bouhoubeiny et al. (2011), Bouhoubeiny (2012), Druault et al. (2012), and Thierry et al. (2021c), the large mesh size on the trawl body without liner would facilitate the flow passage through the trawl, which will increase the probability of escape by juvenile krill and improve the size selectivity of the trawl. Krag et al. (2014) showed that the length of the mature Antarctic krill varies between 37 and $50 \mathrm{~mm}$ and can be caught at 32 by $16 \mathrm{~mm}$ mesh size such as the mesh size of the liner used in this study. However, for the trawl with $50 \%$ liner, more than half of the trawl body is constituted by the large mesh $(400 \mathrm{~mm})$ without a liner, which will facilitate the escape of krill that contact the mesh. Consequently, while the reduction in liner length by $50 \%$ leads to the reduction in the twine area, which leads to the optimal trawl design with regard to hydrodynamic efficiency and geometry (less drag and higher sweep area), the catching efficiency will be likely lower compared with the traditional trawl due to high escape rates. Therefore, we recommend the trawl with $75 \%$ liner as the design of this trawl will increase energy efficiency by about $12.44 \%$ and catch rates by about $6.52 \%$ compared with the trawl with $100 \%$ liner. Although its performance is lower than that of a trawl with a $50 \%$ liner, its catch efficiency will be greater than that of other trawls. 


\section{CONCLUSION}

This study was carried out to evaluate the impact of liner length through model tests in a flume tank to predict the full-scale engineering performance of the midwater trawl net. Four 1/35th scale trawl models were designed and tested in the flume tank using seven towing speeds, five door spreads, three heavy bob weights, and four ratios $F / G$. The geometrical shape of each trawl was obtained using a series of images selected from the recorded video footage. These images were used to extract the coordinates of characteristic points of the model trawl. Below are the main conclusions:

(1) The reduction in the twine area led to a decrease in bridle tension of about $26.16,19.78$, and $12.44 \%$ by using the trawl without liner, with 50 , and $75 \%$ liner, respectively.

(2) The reduction in the liner length led to an increase in net mouth opening by $9.33,5.38$, and $2.63 \%$ by using the trawl without, 50 , and $75 \%$ liner.

(3) The trawls with 50 and $75 \%$ liners have very good performance in terms of hydrodynamic drag and mouth opening. But considering a reduction in catch efficiency due to excessive escape of krill for the trawl with $50 \%$ liner, we recommend the trawl with $75 \%$ liner as the optimal design.

(4) Further work is required to investigate the catch performance of the optimal design trawl through sea trials and to analyze the effect of the liner on the turbulent flow to further understand the undelaying factors influencing the selectivity of this fishing gear.

\section{REFERENCES}

Bairstow, F., Gastauer, S., Finley, L., Edwards, T., Brown, C. T. A., Kawaguchi, S., et al. (2021). Improving the accuracy of krill target strength using a shape catalog. Front. Mar. Sci. 8:658384. doi: 10.3389/fmars.2021.65 8384

Balash, C., Sterling, D., Binns, J., Thomas, G., and Bose, N. (2015). The effect of mesh orientation on netting drag and its application to innovative prawn trawl design. Fish. Res. 164, 206-213. doi: 10.1016/j.fishres.2014.11.018

Bouhoubeiny, E. (2012). Caractérisation de L'écoulement Autour de Structures Souples et Poreuses : Application aux Engins de Pêche. PhD. thesis, Paris: University Pierre and Marie Curie.

Bouhoubeiny, E., Germain, G., and Druault, P. (2011). Time-resolved PIV investigations of the flow field around rigid cod-end net structure. Fish. Res. 108, 344-355. doi: 10.1016/j.fishres.2011.01.010

Broadhurst, M. K., Balash, C., Sterling, D. J., et al. (2017). Effects of knot orientation on the height and drag of a penaeid trawl. Fish. Res. 186, 48-54. doi: 10.1016/j. fishres.2016.08.003

Broadhurst, M. K., Sterling, D. J., and Millar, R. B. (2015). Increasing lateral mesh openings in penaeid trawls to improve selection and reduce drag. Fish. Res. 170, 68-75. doi: 10.1016/j.fishres.2015.05.014

Druault, P., and Germain, G. (2016). Analysis of hydrodynamics of a moving trawl codend and its fluttering motions in flume tank. Eur. J. Mechan. B/Fluids 60, 219-229. doi: 10.1016/j.euromechflu.2016.06.010

Druault, P., Bouhoubeiny, E., and Germain, G. (2012). POD investigation of the unsteady turbulent boundary layer developing over porous moving flexible fishing net structure. Exp. Fluids 53, 277-292. doi: 10.1007/s00348-012-1 289-1

Engås, A., Eriksen, E., Jørgensen, T., Pavlenko, A., Prokhorova, T., and Aasen, A. (2014). Harstad Trawl: Trials of Ruffled Small-Meshed Inner Nets to Reduce Loss

\section{DATA AVAILABILITY STATEMENT}

The raw data supporting the conclusion of this article will be made available by the authors, without undue reservation.

\section{AUTHOR CONTRIBUTIONS}

HT: investigation, conceptualization, writing original draft, funding acquisition, review and editing the original draft, data curation, and validation. BN: investigation, methodology, software, writing original draft, data curation, conceptualization, and validation. AP: formal analysis and writing. $\mathrm{PH}$ : investigation, review and editing the original draft, and supervision. XL: investigation, funding acquisition, review and editing the original draft, data curation, and supervision. FH: investigation, conceptualization, validation, data curation, and supervision. All authors contributed to the article and approved the submitted version.

\section{FUNDING}

This study was financially sponsored by the National Natural Science Foundation of China (Grant No. 31902426), the Shanghai Sailing Program (19YF1419800), and a special project for the exploitation and utilization of Antarctic biological resources of Ministry of Agriculture and Rural Affairs (D-8002-18-0097).

and Clogging of Small Organisms and Tests of a New Codend. Bergen: Institute of Marine Research. Cruise report.

Engås, A., Eriksen, E., Pavlenkov, A., Prokhorova, T., Øvredal, J. T., and Aasen, A. (2013). Trials of Inner Net to Reduce Clogging of Harstad Trawl-net by Small Fish. Bergen: Cruise report. Institute of Marine Research.

Feng, C. L., Huang, H. L., Zhou, A. Z., Zhang, X., Liu, J., Xu, G. D., et al. (2012). Performance optimization of a trawl for Antarctic krill. J. Fish. Sci. China 24, $1-2$.

Feng, C., Liu, J., Zhang, Y., Wang, Y., Zhang, X., Zhou, A., et al. (2017). Structure improvement design and performance experiment of Antarctic krill trawl net. Trans. Chinese Soc. Agricultural Eng. 33, 75-81.

Fiorentini, L., Sala, A., Hansen, K., Cosimi, G., and Palumbo, V. (2004). Comparison between model testing and full-scale trials of new trawl design for Italian bottom fisheries. Fish. Sci. 70, 349-359. doi: 10.1111/j.1444-2906.2004. 00813.x

Herrmann, B., Krag, L. A., and Krafft, B. A. (2018). Size selection of antarctic krill (Euphausia superba) in a commercial codend and trawl body. Fish. Res. 207, 49-54. doi: 10.1016/j.fishres.2018.05.028

Hu, F., Matuda, K., and Tokai, T. (2001). 'Effects of drag coefficient of netting for dynamic similarity on model testing of trawl nets'. Fish. Sci. 67, 84-89. doi: 10.1046/j.1444-2906.2001.00203.x

Hu, F., Matuda, K., Tadashi, T., and Haruyuki, K. (1995). Dynamic analysis of midwater trawl system by a two-dimensional lumped mass method. Fish. Sci. 61, 229-233. doi: 10.2331/fishsci.61.229

Hu, F., Tadashi, T., Seiichi, T., Daisuke, S., Hiroshi, I., and Yasuhisa, H. (2004). The performance of the new circulating water channel of Tokyo University of marine science and technology. Japanese Soc. Fish. Eng. 41, $153-163$.

Juáres, M. A., Casaux, R., Corbalán, A., Blanco, G., Pereira, G. A., Perchivale, P. J., et al. (2018). Diet of Adélie penguins (Pygoscelis adeliae) at stranger point (25 
de Mayo/King George Island, Antarctica) over a 13-year period (2003-2015). Polar Biol. 41, 303-311. doi: 10.1007/s00300-017-2191-3

Juáres, M. A., Grech, M. G., Ricardo, C., Negrete, J., Fógel, J., and Coria, N. R. (2021). Size structure of Antarctic krill inferred from samples of Pygoscelid penguin diets and those collected by the commercial krill fishery. Mar. Biol. 168:22. doi: 10.1007/s00227-021-03831-0

Kawaguchi, S., and Nicol, S. (2020). "Krill fishery," in Fisheries and Aquaculture eds G. Lovrich and M. Thiel (Oxford: Oxford University Press), 137-158. doi: 10.1093/oso/9780190865627.003.0006

Krafft, B. A., and Krag, L. A. (2015). Assessment of mortality of antarctic krill (euphausia superba) escaping from a trawl. Fish. Res. 170, 102-105. doi: 10. 1016/j.fishres.2015.05.019

Krag, L. A., Herrmann, B., Iversen, S. A., Engås, A., Nordrum, S., and Krafft, B. A. (2014). Size Selection of Antarctic Krill (Euphausia superba) in Trawls. PLoS One 9:e102168. doi: 10.1371/journal.pone.0102168

Lee, J., Lee, C.-W., Songho, P., Jieun, K., Subong, P., and Taeho, K. (2018). Development of a low-energy midwater trawl with different combinations of trawl nets and trawl doors through model experiments. Fish. Sci. 84, 323-334. doi: 10.1007/s12562-017-1158-1

Li, L. Z., Chen, S., Yang, J. L., Liu, J., Wu, Y., Qu, T. C., et al. (2017). Performance analysis of the four-panel mid-water trawl for Antarctic krill fishery. J. Fish. Sci. China 24, 893-901.

Nguyen, T. X., Winger, P. D., Orr, D., Legge, G., DeLouche, H., and Gardner, A. (2015). Computer simulation and flume tank testing of scale engineering models: how well do these techniques predict full-scale at-sea performance of bottom trawls? Fish. Res. 161, 217-225. doi: 10.1016/j.fishres.2014. 08.007

Nicol, S., and Foster, J. (2016). "The Fishery for Antarctic Krill: its Current Status and Management Regime, in Biology and Ecology of Antarctic Krill, ed V. Siegel (Berlin: Springer International Publishing). doi: 10.1007/978-3-319-292 79-3_11

Pshenichnov, L. (2009). On Incidental Mortality of Antarctic krill at Krill Fishery. Hobart, Tas: CCAMLR. CCAMLR WG-EMM-09/11.

Punchihewa, N., and Krishnarajah, S. (2013). Trophic position of two mysid species (crustacea: Mysidacea) in an estuarine ecosystem in Auckland, New Zealand, using stable isotopic analysis. Am. J. Mar. Sci. 1, 22-27.

Sala, A., Lucchetti, A., Palumbo, V., and Hansen, K. (2008). "Energy saving trawl in Mediterranean demersal fisheries," in Maritime Industry, Ocean Engineering and Coastal Resources, eds G. Soares and Kolev (London: Taylor \& Francis Group).

Sendłak, H. (1998). The effect of the application of Dyneema fibers on the parameters of opening and drag of a trawling system with the pelagic trawl WP 4/8 234/720x194/540. Bull. Sea Fish. Institute 1, 51-61.

Sterling, D., and Balash, C. (2017). Engineering and catching performance of five netting materials in commercial prawn-trawl systems. Fish. Res. 193, 17-24.

Thierry, B. N. N., Tang, H., Xu, L., You, X., Hu, F., Njomoue, P. A., et al. (2020a). Hydrodynamic performance of bottom trawls with different materials, mesh sizes, and twine thicknesses. Fish. Res. 221:105403. doi: 10.1016/j.fishres.2019. 105403

Thierry, B. N. N., Tang, H., Njomoue, P. A., Xu, L., Hu, F., and You, X. (2020b). Comparative study on the full-scale prediction performance of four trawl nets used in the coastal bottom trawl fishery by flume tank experimental investigation. Appl. Ocean Res. 95:102022.

Thierry, B. N. N., Tang, H., Xu, L., Hu, F., Shuchuang, D., Njomoue, P. A., et al. (2021a). Comparison between physical model testing and numerical simulation using two-way ?uid-structure interaction approach of new trawl design for coastal bottom trawl net. Ocean Eng. 233:109112. doi: 10.1016/j.oceaneng.2021. 109112

Thierry, N. N. B., Tang, H., Xu, L. X., Hu, F., You, X. X., David, M. A., et al. (2021b). Identifying the turbulent flow developing inside and around the bottom trawl by electromagnetic current velocity meter approach in the flume tank. J. Hydrodyn. 33, 636-656. doi: 10.1007/s42241-021-0058-50

Thierry, B. N. N., Tang, H., Achile, N. P., Xu, L., Zhou, C., and Hu, F. (2021c). Experimental and numerical investigations of the hydrodynamic characteristics, twine deformation, and flow field around the netting structure composed of two types of twine materials for midwater trawls. J. Ocean Univ. China 20, 1215-1235. doi: 10.1007/s11802-021-47404741

Thierry, B. N. N., Tang, H., Achile, N. P., Xu, L., Zhou, C., and Hu, F. (2022). Unsteady turbulent flow developing inside and around different parts of fluttering trawl net in flume tank. J. Fluids Struct. 108:103451. doi: 10.1016/j. jfluidstructs.2021.103451

Underwood, M. J., Rosen, S., Engås, A., Hemnes, T., Melle, W., and Aasen, A. (2016). Flume Tank Testing of a Multiple Inner-Paneled Trawl to Reduce Loss and Clogging of Small Organisms. Bergen: Institute of Marine Research. Cruise report.

Wan, R., Mingxiu, J., Qinglong, G., Liuyi, H., Hui, Ch, Fenfang, Z., et al. (2019). Hydrodynamic performance of a newly-designed Antarctic krill trawl using numerical simulation and physical modeling methods. Ocean Eng. 179, 173179. doi: 10.1016/j.oceaneng.2019.03.022

Wileman, D., and Hansen, K. (1988). Estimation of the Drag of Trawls of Known Geometry. Hirtshals Denmark: The Danish Institute of Fisheries Technology and Aquaculture.

Winger, P. D., DeLouche, H., and Legge, G. (2006). Designing and testing new fishing gears: the value of a flume tank. Mar. Tech. Soc. J. 40, 44-49. doi: $10.4031 / 002533206787353240$

Xu, L. X. (2004). Fishing Gear Theory and Design. Beijing: China Agriculture Press. Xu, P. X., Xu, L. X., Meng, T., Huang, H. L., Zhang, X., Zhou, A. Z., et al. (2015). Comparative analysis on the performance of Japan and South Korea Antarctic krill mid-water trawls with small mesh sizes. J. Fish. Sci. China 22, 837-846.

Zhou, A. Z., Feng, C. L., Zhang, X., and Wang, Y. J. (2016). Experiment and research of krill trawl net. Mar. Fish. 38, 74-82.

Zhou, A., and Feng, C. (2011). Experiment and research of krill trawl net. J. Modern Fish. Inform. 26, 6-9.

Conflict of Interest: The authors declare that the research was conducted in the absence of any commercial or financial relationships that could be construed as a potential conflict of interest.

Publisher's Note: All claims expressed in this article are solely those of the authors and do not necessarily represent those of their affiliated organizations, or those of the publisher, the editors and the reviewers. Any product that may be evaluated in this article, or claim that may be made by its manufacturer, is not guaranteed or endorsed by the publisher.

Copyright (C) 2022 Tang, Nsangue, Pandong, He, Liuxiong and Hu. This is an openaccess article distributed under the terms of the Creative Commons Attribution License (CC BY). The use, distribution or reproduction in other forums is permitted, provided the original author(s) and the copyright owner(s) are credited and that the original publication in this journal is cited, in accordance with accepted academic practice. No use, distribution or reproduction is permitted which does not comply with these terms. 